\title{
Does the CDS MARKet REFleCt REgulatory Climate RISK DISCLOSURES?*
}

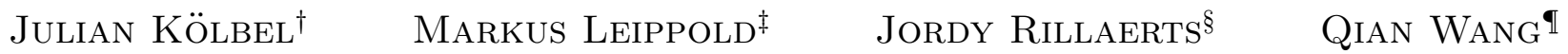

June 2, 2020

\begin{abstract}
Climate change may have a detrimental effect on a firm's financial performance. Using a forward-looking measure of climate risk exposure based on textual analysis of firms' 10-K reports, we assess whether climate risks - as disclosed to the regulator - are priced in the credit default swap (CDS) market. We construct this novel climate risk measure based on BERT, an advanced language understanding algorithm, and adapt it for our purpose. We differentiate between physical and transition risks and find that transition risk increases CDS spreads, especially after the Paris Climate Agreement of 2015. However, we do not find such an effect for physical risk.
\end{abstract}

Keywords: climate risk disclosure, CDS spreads, 10-K filings, physical risks, transition risks, BERT model.

\section{JEL classification: G13, G28, M48}

\footnotetext{
${ }^{*}$ We thank Marco Ceccarelli, Bob Eccles, Jonathan Krakow, Per Östberg, Stefano Ramelli and Alexander Wagner for very helpful comments and discussions. We also thank seminar participants at the BBLS (UZH).

${ }^{\dagger}$ University of Zurich, Department of Banking and Finance, Plattenstrasse 14, 8032 Zurich, Switzerland; julian.koelbel@bf.uzh.ch.

${ }^{\ddagger}$ University of Zurich, Department of Banking and Finance, Plattenstrasse 14, 8032 Zurich, Switzerland; markus.leippold@bf .uzh.ch.

${ }^{\S}$ University of Zurich, Department of Banking and Finance, Plattenstrasse 14, 8032 Zurich, Switzerland; jordy.rillaerts@bf.uzh.ch.

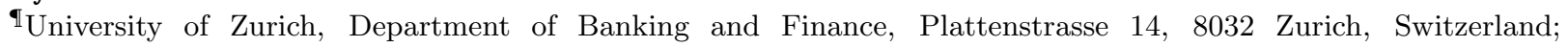
qian.wang@bf .uzh.ch.
} 


\section{Introduction}

"Without effective disclosure of these risks, the financial impacts of climate change may not be correctly priced - and as the costs eventually become clearer, the potential for rapid adjustments could have destabilizing effects on markets."

Michael Bloomberg, chairman on the TCFD, Financial Stability Board (2017)

Climate change is continuing to dominate headlines, and the impact of climate change-related risks on financial and capital markets is a growing concern for companies, investors, and regulators worldwide. Climate risks entail physical risks that emerge from extreme weather events as well as transition risks due to regulatory reforms intended to combat global warming. Such risks feature prominently among the most likely and most impactful risks identified by the World Economic Forum in its outlook on global long-term risk (WEF, 2020) 11 According to a recent survey, many large institutional investors believe that climate risks have "significant financial implications" for firms (Krueger et al., 2019). Also, regulators recognize that climate change poses material risks to companies and that such risks need to be disclosed to investors (SEC, 2010).

A key question in the nascent literature on climate risks is the extent to which financial markets already incorporate climate risks into prices. There is growing evidence that transition risks are priced, especially risks associated with a firm's carbon emissions 2 level, as these firms are most likely to be subjected to future regulation. Equity prices worldwide contain a "carbon premium" (Bolton and Kacperczyk, 2020), and also option prices (Ilhan et al., 2019b) indicate greater risk for firms with carbon-intensive business models. However, physical risks are less explored, and there is still much uncertainty whether they are incorporated into prices. While Baldauf et al. (2020) find that flood risk affects real estate prices under certain conditions, Hong et al. (2017) observe that market prices of food firms are not incorporating climate-change risks $3^{3}$ Thus, considering the various effects

\footnotetext{
${ }^{1}$ In terms of likelihood, the top five identified risks were all environmental issues (Extreme weather, Climate action failure, Natural disasters, Biodiversity loss, and Human-made environmental disasters). In terms of impact, three out of the top five risks are related to climate change (Climate action failure, Biodiversity loss, Extreme weather), see WEF (2020).

${ }^{2}$ For simplicity, we use the term carbon emissions to refer to all types of greenhouse gas emissions.

${ }^{3}$ However, Hong et al. (2017) focus on the predictability of future realized returns to investigate the relation between climate change risks and market efficiency, the study therefore does not directly address the question whether investors understand climate change risks and concurrently price such risks into asset prices.
} 
of different climate risks on different financial contracts, the literature has only explored in a limited number of settings whether financial markets price climate risks.

A closely related question is how firms should disclose climate risks so that market participants can incorporate them into their decisions. There are several regulatory approaches to this question. The US Securities and Exchange Commission (SEC) adopts a principles-based approach ${ }^{4}$, where corporations are required to self-identify climate-related risks that are material to their business in their 10-K report (SEC, 2010). A key advantage of the SEC's approach is that it is mandatory and that a failure to disclose climate risks may result in litigation 5 As a result, investors can be reasonably sure to obtain climate risk information from all firms that are regulated by the SEC. However, the SEC's approach has been criticized for being too flexible and not requiring any standardized information or quantitative metrics (see Palmiter (2015) and Wasim (2019)). In fact, according to a recent survey (Ilhan et al., 2019a), many institutional investors deem the current quality and quantity of climate risk disclosure insufficient. As a result, it is not apparent whether investors are pricing the climate risk information contained in 10-K reports.

Against this backdrop, the present paper analyzes whether the current US regulatory framework for climate risk disclosure affects the pricing of credit default swaps (CDS). Climate risk exposure may potentially diminish a firm's profitability and affect its ability to fulfill its financial obligations over time and, hence, may lead to increased credit risk ${ }^{6}$ At least since recently, rating agencies occasionally account for climate risks. According to Michael Wilkins, who leads Standard and Poor's sustainable finance group, almost ten percent of all their assessments took climate risk into account for assessing a firm's credit rating (Mathiesen, 2018).

For our analysis, we focus on CDS contracts. Compared to credit ratings, which offer a relative ranking of credit risks under the physical probability measure, CDS spreads ultimately reflect the market price for the underlying entity's credit risk. Hence, unlike credit ratings, CDS spreads

\footnotetext{
${ }^{4}$ In contrast, the Task Force on Climate-Related Financial Disclosures (TCFD), for example, adopts a standardsbased approach, calling on firms to disclose a specific set of information and metrics. The application of TCFD guidelines, however, is so far purely voluntary.

${ }^{5}$ For example, ExxonMobil, an American multinational gas and oil corporation, was sued by the New York's attorney general for misleading investors by not complying to reporting regulations and downplaying the risk climate change would have on its business, see The New York Times from October 24, 2018.

${ }^{6} \mathrm{~A}$ decrease in profitability due to climate-risk exposure also underlies the general equilibrium model developed in Hsu et al. 2018), which is based on the political uncertainty model in Pástor and Veronesi 2012. 2013).
} 
incorporate a risk premium, and our goal is to investigate whether climate risk influences this risk premium. As an alternative, we can also analyze corporate bond spreads. However, CDS spreads have two crucial advantages. First, the CDS contract is typically traded on standardized terms. At the same time, bond spreads are more likely to be affected by differences in contractual arrangements, and hence, are likely contaminated by a liquidity premium (Longstaff et al., 2005). Second, Blanco et al. (2005) and Zhu (2006) show that CDS spreads tend to respond more quickly than bond spreads to changes in market and credit conditions. Furthermore, given that there are CDS contracts with maturities of up to 30 years, they allow us to explore the impact of climate risks in the mid- and long term.

We contribute to the literature in several ways. First, we introduce a novel climate risk score (henceforth Climate Risk). To quantify the climate risks that companies report under the SEC's disclosure regime, we use a state-of-the-art natural language processing (NLP) technique called BERT (Bidirectional Encoder Representations from Transformers), developed by Devlin et al. (2019). Mainly, we use BERT to quantify the relative importance of climate risks compared to other risks that are disclosed in Item 1.A of a firm's 10-K report. We show that the technique significantly improves upon older NLP methods, contributing to a small but growing literature that uses artificial intelligence to identify climate-relevant information in text data $7^{7}$ Specifically, our measure represents an improvement over earlier studies that quantify climate risks from $10-\mathrm{K}$ reports using a simple "bag-of-words" approach (Berkman et al., 2019).

Measuring climate-risks disclosures in Item 1.A of 10-K reports affords several advantages. First, as it relies on mandatory disclosure, it avoids the problems of strategic non-disclosure and greenwashing Lyon and Maxwell (2011). Second, it is a forward-looking risk measure that corresponds to potential risks in the future, unlike, for example, a firm's carbon emissions. Third, by focusing on Item 1.A, in which firms are required to disclose any risks to warn investors and potential investors adequately, we can ensure that we capture the risk-related impact of climate change on a firm's business 8 Fourth, our methodology encompasses the entire spectrum of climate risks, including both

\footnotetext{
${ }^{7}$ See, e.g., Grüning (2011) and Luccioni and Palacios $(2019)$.

${ }^{8}$ In voluntary climate-risk disclosures, companies provide information on the risks and the opportunities related to climate change. In the 10-K reports, this mixing of risk and opportunities may also occur in Item 7, Management's Discussion, and Analysis of Financial Condition and Results of Operations. For this reason, we only focus on Item 1.A.
} 
transition and physical risks, which allows us to create separate risk scores for both transition and physical risks from the same regulatory source.

As a second contribution, we provide evidence that CDS spreads are responsive to climaterisk disclosures, at least in industries where climate risks are expected to be material. Hence, our paper is the first study to demonstrate that climate risk disclosures influence CDS spreads, thus complementing the existing literature on the pricing of climate risks. The fact that disclosed climate risks are priced in CDS markets is an indication that climate risks are perceived as so substantial that they may affect creditors. While our results are in line with existing findings for equity prices, they add one important aspect. A "carbon premium" on equity returns could be driven by risk perception, but it could also be driven by divestment policies that reflect investor's moral tastes Hong and Kacperczyk, 2009; Bolton and Kacperczyk, 2020). This alternative hypothesis is implausible in the CDS market, given that it is dominated by professional investors that are in the business of hedging risks. Hence, our results are a signal that climate risk is indeed interpreted as a financial risk.

However, and this is our third contribution, we also find that only transition risks are being priced, but not the physical risks of climate change. This finding suggests that the market responds distinctively to transition and physical risks. While this finding is also in line with prior literature, our study's advantage is that both measures come from the same source. If companies disclose transition risks in their 10-K reports, one can expect that they disclose physical risks as well. Transition risk is more imminent and more sensitive to political developments. In line with that, we find that the price effect of transition risk increased with the Paris Climate Accord of 2015. The effect of physical risk remains insignificant before and after the Paris Climate Accord. Physical risks may play out over longer time horizons. However, even when analyzing CDS contracts extending to up to 30 years and analyzing the term structure of CDS spreads, we do not find a significant physical risk effect. Thus, currently, physical risks of climate change do not seem to be priced into CDS spreads.

Overall, our results imply that climate risk disclosure as mandated by the SEC fulfills - at least to some extent - its purpose of informing investors about material risks and thereby limiting the risk of sudden adjustments in the future. While it certainly could be improved, we present evidence that the disclosed information affects the perceived riskiness of corporate debt, which implies that 
investors make use of the disclosed information. At the same time, our results leave open whether the current approach to disclosure is effective for physical risks related to climate change. Given the sizeable physical impact that climate change may have, our finding points at a critical blind spot for companies, investors, and regulators. According to a study by the The Economist Business Intelligence Unit (2015), up to 30\% of the world's total stock of manageable assets may be at risk due to climate change impacts, highlighting the potential costs of climate change.

Our paper is closely related to studies on voluntary climate-risk disclosure. For instance, Liesen et al. (2017) assess and confirm the relevance of information in corporate disclosures of quantitative carbon emissions on asset prices. Kim et al. (2015) find that a firm's carbon intensity increases the cost of equity, but that voluntary disclosure is not awarded by the market and does not weaken the negative impact on the cost of equity. In contrast, Jung et al. (2018) show that the penalty that a firm with high carbon-related risks receives is mitigated with the firm's climate awareness, proxied by the willingness to respond to the Climate Disclosure Project (CDP) survey. Matsumura et al. (2018) provide similar evidence, showing that the market penalizes firms for not disclosing climate change risk in their 10-K filings by increasing their implied cost of equity, especially in those industries where it is considered material. The idea in Matsumura et al. (2018) is that the choice to disclose on climate-change risk signals awareness and is rewarded by a lower implied cost of equity. Our study is also related to general risk assessments, other than climate-specific risk, based on 10-K filings. See, e.g., Hope et al. (2016); Friberg and Seiler (2017); Lopez-Lira (2019). Most of this literature finds a significant effect of the disclosed risks, providing evidence that current disclosure methods do provide relevant information and add value.

We organize the remainder of this paper as follows. In Section 2, we discuss how we measure climate-risk related disclosure, and we introduce our own methodology on how to extract climaterelevant information from the 10-K filings. Then, in Section 3, we give an overview of the data, which underlies our study, and in Section 4, we present descriptive statistics and perform some preliminary analysis. Section 5 reports and discusses the main results. Section 6 concludes. 


\section{Measuring climate risk}

Climate risk is a recent phenomenon in finance, and there is to date no consensus on how to measure it empirically. The majority of recent studies use either carbon emissions (Chen and Gao, 2012; Andersson et al., 2016; Liesen et al., 2017; Jung et al., 2018; In et al., 2019; Ilhan et al., 2019b; Ramelli et al., 2018) or ESG scores (Görgen et al., 2019) to proxy for climate risk.99 Ginglinger and Moreau (2019) use a forward-looking measure, "Climate Risk Impact Screening," developed by the commercial data provider Carbone 4. Ramelli et al. (2018) complement carbon emission with data on climate responsibility from the ESG rating agency Vigeo Eiris. Finally, Delis et al. (2019) hand-collect data on fossil fuel reserves from the firm's annual reports.

Our approach to measuring climate risk relies on analyzing regulatory disclosure to the US Securities and Exchange Commission (SEC). Publicly listed companies in the US are required to file audited annual reports in the form of 10-K filings. Since 2006, the SEC requires that the 10-K reports include a specific section (Item 1.A) for firms to self-identify those risks that they see as significant risk factors to their business. With the increasing awareness that climate risk may pose an economic threat for the corporate world, the SEC provided in 2010 some interpretive guidance, clarifying the existing disclosure requirements as they apply to business or legal developments relating to climate change. In that guidance, the SEC identified four existing items in Regulation S-K ${ }^{10}$ that may require disclosure related to climate change: description of the business, legal proceedings, risk factors, and management's discussion and analysis of financial condition and results of operations, or MD\&A 11

Relying on regulatory filings to estimate climate risks offers several significant advantages over the available alternatives, e.g., carbon emissions. First, companies are requested to disclose all kinds of climate-related risks in their 10-K filings. Carbon emissions, in contrast, do not capture all aspects of climate risk. Carbon emissions are probably a reasonable proxy for regulatory risk, given that a fundamental objective of future regulation is to drive emissions downwards. However, carbon emissions do not indicate a firm's physical risk exposure. Physical risks of climate change, although

\footnotetext{
${ }^{9}$ Examples of carbon emissions data providers are Carbon Disclosure Project (CDP), Trucost, Clean Energy Regulator (Australia), South Pole Group, and MSCI. The primary ESG rating providers are MSCI, Sustainalytics, Asset4, Vigeo Eiris, and Oekom ISS.

${ }^{10}$ Regulation S-K lays out a range of mostly qualitative reporting requirements under the purview of the SEC.

${ }^{11}$ See, $\operatorname{SEC}(2010)$.
} 
driven by carbon emissions, may affect firms regardless of their level of carbon emissions. Regulatory filings reflect both the transition risks and the physical risks of climate change.

Second, 10-K reports contain a description of forward-looking risks, whereas carbon emissions data is backward-looking operational performance. Past emissions are not necessarily representative for future emissions, and even less for future risk exposure. Firms may be able to outsource emissionintensive processes in the future or pass on cost increases to customers. In contrast, risks disclosed in SEC filings specifically refer to a company's forward-looking risk exposure. Therefore, they may provide a better proxy for future exposure. This forward-looking aspect of regulatory filings is deliberate, as investors commonly seek to obtain and incorporate forward-looking information. A similar point was also made by Jung et al. (2018), who show that lenders do incorporate a forwardlooking attitude in their lending decisions.

Third, and most importantly, 10-K filings are mandatory and enforceable. While an increasing number of companies report their carbon emissions, for example, via the CDP, such disclosure is voluntary. Also, ESG ratings are partially based on information that companies provide voluntarily. This raises two problems. First, companies may strategically choose not to disclose, especially when managers fear that the information will be perceived as unfavorable by investors Lyon and Maxwell (2011). Second, voluntary disclosure is not routinely audited or enforceable so that investors can not be sure that the information is correct. As a result, with voluntary disclosure, one might underestimate the risks of precisely those companies that have the highest risk exposure. In contrast, the disclosure of climate risks in 10-K filings is legally required for all companies, and any misreporting or negligence could result in legal consequences ${ }^{12}$ Consequently, the accompanying litigation risk serves as a third-party check for the quality and reliability of the disclosed information.

However, there are also some disadvantages related to regulatory filings. First, climate risk disclosure is mostly textual data. In contrast, carbon emissions are numerical data, which are easier to deal with in risk management. At the same time, there remains some discretion for companies regarding how they report and which language they use. As a result, it is difficult to assess when something crosses the line of under-reporting or when something is more a matter of interpretation

\footnotetext{
${ }^{12}$ For instance, in October 2018, a lawsuit was filed by the New York state attorney general against Exxon Mobil Corporation for underestimating their climate risk exposure in their annual report (10-K) and deceiving investors
} 
than actual fact-based information. Besides, while deceiving investors is a punishable offense (as in the Exxon Mobil case), firms might think the risk of prosecution might outweigh the actual costs of full transparency. Hence, in that case, the information presented in SEC filings would not be a fully adequate representation of actual firm-specific climate risk exposure. Lastly, many companies resort to boilerplate disclosures where the information they provide is almost meaningless. Given these circumstances, extracting climate-risk relevant information from regulatory disclosures is a subtle task.

\subsection{Previous algorithmic approaches to analyze climate risk disclosure}

Over recent years, a small but growing literature emerged that uses artificial intelligence to identify climate-relevant information in company reports. Traditional approaches from natural language processing (NLP) are based on a pre-defined list of presumably relevant words and then search for these words within the documents ${ }^{13}$ Bag-of-words approaches are prevalent to transform textual into numerical data. However, they come with the substantial drawback of assuming words as discrete entities. Thus, all words are considered to have the same (dis-)similarity to each other.

As a remedy, Luccioni and Palacios (2019) represent each word by a multi-dimensional vector to learn similarities between them, i.e., vectors of words which often appear in similar context are close in terms of Euclidean distance ${ }^{14}$ The authors exploit these representations using a set of hand-picked keywords (biodiversity, carbon, climate, ecology, environment, emission, pollution, sustainable) and extending it by retrieving the ten closest words in the word vector space. However, the authors do not justify why their word selection fits the purpose of analysis. Moreover, Kim and Kang (2018) shows that climate-related wording of different sources could differ substantially. While word embeddings are already a significant improvement on bag-of-words, they still do not account for context. Thus, negations are naturally not considered by these approaches. Hence, with both these methods, we are still far from understanding entire sentences.

Recently, Berkman et al. (2019) use a climate risk measure derived from SEC filings. This measure

\footnotetext{
${ }^{13}$ For example, Grüning (2011) uses so-called bag-of-words to evaluate annual reports for ten different information dimensions.

${ }^{14}$ For instance, raise and increase have similar word vectors. Thus, synonyms are naturally seen as words with very similar meanings.
} 
is developed through the climate disclosure search tool from CERES and CookESG Research, for which data is publicly available on the website of either organization 15 The measure is constructed by using rules-based text analysis algorithms. First, in each 10-K report, excerpts related to climate risk are identified based on a keyword dictionary, constructed in an iterative process. Second, these individual excerpts are given a relevance score, a function of language relevance, and directness of addressing the issue at hand. Finally, a global disclosure score is assigned to each 10-K report by summing up the relevance scores of the individual excerpts within that particular report.16

Originally, CERES and CookESG advertise their tool as an instrument for investors to help them understand how companies tackle risks and opportunities they face from climate change, hence not purely a representation of risk exposure. Nevertheless, Berkman et al. (2019) find that the measure constructed as such does indeed capture climate risk. They argue that more elaborate disclosures reflect higher climate risk exposure in general. However, given the apparent drawbacks of these traditional NLP methods, we believe that there is room for improvement. For this reason, we introduce our own scoring technology that relies on the state-of-the-art natural language processing technique called Bidirectional Encoder Representations from Transformers (BERT) developed by Devlin et al. (2019). To assess this new method's performance, we include the climate score of CERES and CookESG Research in our analysis. For the remainder of this paper, we will refer to their measure as CookESG.

\subsection{Analyzing climate risk disclosure using BERT}

We have recently witnessed enormous progress in text understanding with the introduction of pre-trained neural language models like BERT. Unlike traditional word embeddings, BERT is a contextual model, i.e., the representation of a word is a function of the entire input text, respecting the word dependencies and sentence structures. BERT is pre-trained on a large number of documents so that the contextual representations encode general language patterns. Contextual neural language models like BERT have outperformed traditional word embeddings on various NLP tasks (see, e.g.,

\footnotetext{
${ }^{15}$ Data can be obtained from CERES or CookESG

${ }^{16}$ For a more detailed explanation of the construction of the measure and some examples, we refer to appendices $\mathrm{A}$ and B of Berkman et al. (2019).
} 
Peters et al. (2018)). Motivated by these new achievements, we intend to leverage BERT to provide a deeper text understanding of climate-risk relevant sentences in the 10-K reports.

For the construction of our BERT-based climate risk measure, our focus is on Item 1.A only. While firms are specifically obliged to report relevant risk factors under Item 1.A, there are no such obligations for the remainder of the report. Matsumura et al. (2018) have identified the management discussion in Item 7 as an additional source for climate-related disclosure, in which firms show their awareness and understanding of the risks at hand and elaborate on potential (future) actions. However, we argue that the mentioning of climate risk in Item 7 is more of an indication of awareness than risk. Since CDS spreads should be more driven by the risk component, we restrict our analysis to Item 1.A 17

We use BERT to perform two different tasks. In the first task, we check whether climate-relevant topics are mentioned in Item 1.A (CN task). In the second task, we assess whether climate-related topics are concerned about physical or transition risks (TP task). Each of the methods above gives us raw scores for each sentence of the SEC filings that represent the probability for that sentence being related to climate risk, physical risk, or transition risk. To aggregate the raw score, we perform the following procedure. Whenever the raw score is above a given threshold, it is counted as one and zero otherwise. We set this threshold to 0.818 Next, we take the average of these one-zero values for a given document. This way, we control for the actual file-length and obtain a sense of relative importance of climate risk compared to other disclosed risks. We obtain the aggregate document score 19

We implement different algorithms and versions of BERT and compare them against a baseline model, which represents the traditional approach to such a classification problem. This baseline model is similar to the approach underlying the CookESG measure.

Baseline: For each labeled sentence, we use the bag-of-word representation. We remove common

\footnotetext{
${ }^{17}$ As a robustness check, we also included Item 7 in our analysis. We found similar results regarding the impact of climate disclosure on CDS prices, but the results are less clear-cut than those we obtain when considering Item 1.A.

${ }^{18}$ Results are robust for thresholds ranging from 0.5-0.95, indicating that our BERT model discriminates well between non-climate and climate-related sentences.

${ }^{19}$ Alternatively, we could take the sum of these zero-one scores for a given document. This procedure is similar in spirit to our first measure CookESG. Using the summation instead of the average as an aggregation rule, we do not find different results or draw different conclusions. Therefore, for reporting purposes, we do not further look at this procedure.
} 
stop words and keep the top 300 words as the features. As the baseline methodology, we choose a random forest. We do not restrict the maximum depth of the tree since we avoid overfitting by only keeping the most frequent words. The number of trees is set to 50 .

BERT: BERT (Devlin et al., 2019) is a contextualized word representation model that is based on a masked language model and pretrained using bidirectional transformers (Vaswani et al., 2017). It obtains state-of-the-art performance on many NLP tasks while requiring minimal task-specific architectural modification. Here, we utilize the pre-trained Uncased-BERT-Base with two additional fully connected layers (both of size 128) and fine-tune the model with our data set.

Multi-task BERT: Multi-task learning is well suited for exploiting shared knowledge among multiple related tasks. When there are several available tasks in a target domain, it is interesting to check whether it still brings benefits to fine-tune BERT on all the tasks simultaneously. Since both TP and GSRM tasks are focused on the climate domain, we hypothesize that there might be some synergy across tasks. We also add a task to classify sentences from climate-related against non-climate related, which serves similarly as a penalty to classify non-climate sentences into any TP or GSRM categories. All the tasks share the BERT layers except for the last two layers (with the same setup as in the single task), which means that each task has a private classifier layer.

BERT with Generalized Cross-Entropy Loss: Errors in training labels can hamper the performance of a deep neural network, and a generalized cross-entropy loss is recently proposed to combat this problem (Zhang and Sabuncu, 2018). In our case, the target class is of high complexity and thus prone to errors. Therefore, we change our loss function from categorical cross-entropy (CCE) to generalized cross-entropy loss (GCE). We refer readers to Zhang and Sabuncu $(2018)$ for a more detailed description. Following the notation of the original paper, we set the parameter $q$ equal to 0.4 .

\subsubsection{Performance on Test Data}

As a source for our training set, we use the sample reports provided in the TCFD (2019) guidelines, which gives us almost a thousand examples (sentences) for the CN and TP tasks. We further collect random sentences that are not climate-related to build the initial data set. We then feed the data 
to our model and train the model for a few epochs. Next, we run the trained model on the 10-K data set and collect the most confusing examples for the current model 20 The confusing examples are sent to human annotators for labeling, and the most confident examples are sent for reviewing as well ${ }^{21}$ We add confident examples together with the most confusing examples to keep the probability distribution of the data not disturbed too much by the confusing examples. We perform this process for several rounds and end up with 2,506 data points for the CN and the TP tasks.

Table 1 provides an overview of the performance for different tasks using the accuracy (Acc) and F1 scores. Clearly, the baseline methodology, which builds on bag-of-words and a random tree, fails in both tasks. Even for the least complex task, the CN task, the accuracy is only 81.07\%. For the TP task, the accuracy falls below 60\%. All BERT-based methodologies provide a substantial improvement over the bag-of-words approach. Hence, previous literature which uses bag-of-words approaches should be interpreted with a grain of salt.

[Table 1 about here.]

For the BERT models, we make the following observations. We find that the BERT-multitask setup helps the climate/non-climate classification, indicating that the TP shares some information on whether the given text is climate-related or not. For the CN task, we obtain almost perfect results with an accuracy of $99.51 \%$ and an F1 score of $99.50 \%$. The results for the TP task are also satisfactory, with the BERT-Single model achieving scores slightly above 90\%. However, the multitask model fails to beat the single model, with scores slightly below $90 \%$. Thus, the inconsistent objectives drive the shared BERT in different directions. Given the above performance analysis, we decide to continue with the BERT-Single model, as it achieves for both the CN and the TP task scores above $90 \%$. In what follows, we will use the score from the BERT-Single model, which we label as ClimateRisk, and CookESG from CERES and CookESG as two competing ways to represent climate risk disclosure within 10-K filings.

\footnotetext{
${ }^{20}$ E.g., if the predicted probabilities for different classes are similar, we consider the examples as confusing examples for our model.

${ }^{21}$ The annotators have a strong finance background and are aware of the TCFD guidelines.
} 


\section{Data}

Our study period is from February 2010 to December 2018. We start in 2010, after the SEC published its special guidance report on how to address climate change disclosure SEC (2010). The variables Climate Risk and CookESG are obtained as described in the preceding section. Both are measured with annual frequency. To construct our sample, we combine this data with CDS spreads and control variables.

We collect CDS spreads from Thomson Reuters Datastream ${ }^{22}$ CDS are fixed-income derivative instruments, offering the protection buyer insurance against a contingent credit event on an underlying reference entity. CDS are traded over the counter (OTC) and quoted by the annuity premium the protection buyer pays the protection seller, the CDS spread, expressed in basis points with respect to the insured notional amount. Our CDS dataset contains daily spreads for 767 single-name CDS contracts for maturities ranging from six months to 30 years. We filtered out observations which are likely to be data errors 23

For the selection of control variables, we choose macroeconomic and firm-specific variables that have been shown to have a potential effect on credit spreads in prior literature, in particular CollinDufresne et al. (2001); Ericsson et al. (2009); Han and Zhou (2015). For macroeconomic controls, we include the risk-free rate $(I R)$ and the general business climate $(B C)$, which we proxy using the 10-year constant maturity Treasury yield (Collin-Dufresne et al., 2001; Ericsson et al., 2009, Han and Zhou, 2015). We obtain this time-series on a daily frequency from the Federal Reserve Economic Data website 24 We allow for the possibility of non-linear dependency on the interest rate by including $I R^{2}$ in the model (Collin-Dufresne et al., 2001; Han and Zhou, 2015).

As firm-specific controls, we include leverage, return-over-assets, and asset volatility. We obtain the book value of total liabilities, net income, and total assets from Compustat to construct the leverage ratio $(L e v)$ and return-over-assets $(R O A)$. The leverage ratio is defined as the ratio between the book value of total liabilities and the sum of the book value of total liabilities and the market

\footnotetext{
${ }^{22}$ Details on the collection process can be found in Appendix $\mathrm{A}$.

${ }^{23}$ Specifically, we filter out negative CDS spreads and observations with values 0 for all maturities except for the five-year maturity. Following Barth et al. (2019), we also drop CDS observations with spreads above 2000bp on any maturity below seven years.

${ }^{24}$ https://fred.stlouisfed.org/.
} 
value of equity. We obtain the total market value of equity from CRSP by multiplying the total shares outstanding with the stock price. $R O A$ is the ratio of net income to total assets. We collect Compustat data on a quarterly frequency, while CRSP data is daily. We align Compustat with CRSP, taking into account the reporting delay by looking for each company separately at its quarterly filing dates and using the values reported as new values from the moment they are reported. Lower frequency data is transformed into higher frequencies by forward filling until the next observation (or in case of no next observation for a reasonable amount of time) ${ }^{25}$

As a proxy for the asset volatility ( $\mathrm{Vol}$ ), we follow Campbell and Taksler (2003) by computing the standard deviation of stock returns using the most recent 180 days. By relying on historical volatility, the results are in line with those of Han and Zhou (2015) using the stock-specific implied volatility. We remark that as an additional alternative, Collin-Dufresne et al. (2001) use the VIX as a proxy for the individual firm's expected volatility, as most of the firms in their sample do not have traded options. However, when we use VIX for our data sample, we get the counter-intuitive result that the VIX has a negative impact on CDS spreads. Therefore, we stick to the method of Campbell and Taksler (2003).

Matching the CDS data with the data from all the other sources, we end up with observations for 447 different CDS contracts from February 2010 to December 2018 ${ }^{26}$ Since data is collected at different frequencies, we make a compromise to the frequency trade-off between these different frequencies and decide on performing monthly regressions. Hence, we resample higher frequency data by taking the average for each month, we repeat and forward fill lower frequency data by taking the last observation for each month 27 Finally, we have data for at least 334 different CDS contracts at each point in time and we have a total of 41752 firm-month observations.

\footnotetext{
${ }^{25}$ In practice, we initially create a (python) data-frame with observations on a daily frequency, which we, later on, resample to a lower frequency for the actual regressions. This procedure is used to make the switch between different frequencies relatively straightforward without dropping any information during the process (e.g., by resampling from monthly to yearly, while monthly data was already transformed once before).

${ }^{26}$ Matching is done by first matching Datastream mnemonics and reference entity names with CIK codes and tickers. Next, we use the CIK codes to collect Compustat data and to find the matching Cusips. Finally, Cusip codes are used for the data collection from the remaining sources

${ }^{27}$ Lower frequency data is, for example, the Compustat data. The observation for a certain month is the value of the most recent filing, and not averaged according to which day of the month the report was filed.
} 


\section{Descriptive statistics}

To gain some overview of our dataset, we provide some descriptive statistics of the independent variables and the CDS spreads and slopes. In Table 2, we report the corresponding mean, standard deviation, skewness, and excess kurtosis together with the minimum, median, and maximum values of the different variables. We find that, compared to ClimateRisk, the CookESG is characterized by a very large skewness and excess kurtosis.

[Table 2 about here.]

Next, we inspect the distribution of companies across different industries. For the industry classification, we use the Sustainability Accounting Standards Board's (SASB) Sustainable Industry Classification System (SICS) ${ }^{28}$ We opt to use the SICS classification in favor of other conventional practices because the SASB's classification is nicely aligned with the objectives of this paper. According to the SASB, the SICS does not focus solely on the common market and financial characteristics, unlike many traditional classifications, but it also emphasizes a company's sustainability profile, like sustainability-related risks and opportunities. As our main focus is on climate risk exposure, such a sustainability-oriented industry classification is perfectly suited for our purpose. Another reason to use SICS is that the SASB has constructed a so-called materiality map based on its classification system on an industry level.

In our analysis, we will use the SASB materiality map in identifying specific SICS-industries for which climate risk is considered a material risk 29 Determining materiality on an industry level is much more straightforward than on the SICS's sector level. Finally, in our regression results we allow for arbitrary correlations in the standard errors for firms with similar sustainability profiles, by clustering on SASB industries. By clustering on industry instead of on an entity level, we take a conservative stance. Opposed to SASB sectors, the SICS's industry classification identifies a sufficiently high number of clusters, according to Petersen (2009), to render unbiased standard errors.

\footnotetext{
${ }^{28} \mathrm{~A}$ full list of all SICS sectors and industries is provided on SASB's webpage https://www.sasb.org

${ }^{29}$ See also, e.g., Matsumura et al. (2018). The most recent version of the SASB materiality map can be found under https://materiality.sasb.org/
} 
[Table 3 about here.]

In Table 3, we present the distribution of our sample across industries. Note that many industries are represented by only a small amount of firms or have a small amount of firm-month observations. Hence, the sample is not very balanced in terms of industries. However, SICS identifies a total of 77 different industries. Hence, 67 of the 77 industries are represented in our sample.

[Figure 1 about here.]

In Panels (a) and (b) of Figure 1, we show how the distribution of ClimateRisk and CookESG, respectively, differs between industries where SASB considers climate risks to be material and nonmaterial. The ClimateRisk measure clearly highlights this distinction, with the average value being about twice as high for industries where climate risks are material. This observation is an indication that ClimateRisk offers a measure that is consistent with the view of the SASB. Hence, we can expect that ClimateRisk discriminates well between material and non-material industries. At the same time, however, there is a considerable dispersion, meaning that the measure discriminates between companies' risk exposures beyond a simple material/non-material dichotomy. Figure 1 also reflects the descriptive statistics in Table 2, which reports a high standard deviation and excess kurtosis for CookESG, but only moderate values for ClimateRisk.

[Figure 2 about here.]

In Figure 2, we present average values for the industries for our climate risk variables, CookESG and ClimateRisk. From these bar plots, we observe some differences in these two measures. Not only are there differences in terms of the relative magnitude across industries, but there are also different orderings. For instance, we find that for the industry 'electronic manufacturing services and original design manufacturers' (EMS \& ODM), the average CookESG is equal to zero, while its average ClimateRisk positions it at rank 15. Another interesting observation is that the importance of climate risk based on ClimateRisk flattens out much smoother than if we use CookESG as a relevant measure. Hence, there are substantial differences in how these two measures rank climate disclosure across industries. 
To get an idea about how many firms are identified by ClimateRisk and CookESG as disclosing climate-related risks, we plot in Panel (a) of Figure 3 the fraction of companies that have a minimum level of climate risk disclosure in their annual 10-K filings. We categorize companies as disclosing if their score surpasses a specific threshold value 30 Panel (b) shows the corresponding graph for the fractions of firms that have a minimum level of either physical or transition climate risk disclosure in their annual 10-K filings.

[Figure 3 about here.]

Figure 3, Panel (a), reveals a further difference between the two climate-disclosure measures. In particular, ClimateRisk turns out to be more conservative than CookESG. The latter measure indicates an increase in the fraction of climate-disclosing companies from $60 \%$ to more than $70 \%$ by the end of 2018. In contrast, until 2015, ClimateRisk shows a fraction that moves in a constant and more modest range from $52 \%$ to $55 \%$, with a tendency to increase lately, presumably due to the Paris Climate accord in $2015{ }^{31}$ For transition and physical climate-risk disclosures, we find that companies are much more concerned about transition than physical risks. We conjecture that the high uncertainty surrounding climate risk's potential physical impact is much more uncertain than the impact due to transition risks arising, e.g., from regulatory changes.

[Figure 4 about here.]

Lastly, in Panels (a) and (b) of Figure 4, we plot the average 5-year CDS spreads over the entire sample period for different rating categories. Spread levels are at their highest levels at the end of 2011, following a steep jump upwards. After this spike, spreads slowly start to decrease, with an intermediate bump in 2016 and towards the end of the sample period. In Panels (c) and (d), we also plot the average CDS spread term structure per rating category. In line with previous literature,

\footnotetext{
${ }^{30}$ We put such a threshold in place to filter out those companies that only put in place the 'obligated' sentence on climate change but do not provide a more elaborated discussion of any relevant risks. For CookESG the minimum score is set at 2 . In contrast, for ClimateRisk it is set at 0.05 .

${ }^{31}$ Using hand-collected firms' decision on climate disclosure, Matsumura et al. (2018) find that the percentage of S\&P500-firms disclosing climate risk remained steady around 50 percent through 2012, growing slightly to about 53 percent in 2016. Hence, we think that our measure ClimateRisk provides an accurate and conservative assessment of climate-related disclosure.
} 
we find that the average term structure of CDS spreads is upward-sloping, except for low-quality firms. A positively sloped term structure reflects the intuition that a firm's credit quality declines over time, resulting in higher costs of default protection and CDS spreads. CDS spreads may also reflect the risk premium that investors require as a compensation for their exposure to unexpected future credit losses ${ }^{32}$ We find that the average term structure usually flattens out at a time-horizon of 10 years. Hence, for our empirical analysis, we will focus mostly on the short end of the CDS curve, namely the 5-year CDS spreads and the slope of the spreads up to 10 years.

\section{$5 \quad$ Regression results}

For our empirical analysis, we are interested whether climate risk as disclosed by the SEC's 10-K filings impact both the CDS spreads and the slope of the CDS term structure. By additionally looking at the slope of the term structure, we might find some indication about the timing of climate risk, i.e., at what time horizon climate risks are expected to materialize. Hence, we estimate the following set of one-month ahead forecasting regressions:

$$
\begin{aligned}
& \Delta S_{i, t+1}^{m}=\beta \Delta C R_{i, t}+\Phi \Delta X_{i, t}+\Theta \Delta Y_{t}+\epsilon_{i, t+1}, \\
& \Delta Y_{i, t+1}^{m, n}=\beta \Delta C R_{i, t}+\Phi \Delta X_{i, t}+\Theta \Delta Y_{t}+\epsilon_{i, t+1},
\end{aligned}
$$

where by $S_{i, t+1}^{m}$ we denote the next month's (average) $m$-year spread and by $Y_{i, t+1}^{m, n}$ the slope of the CDS term structure between year $m$ and $n$, and $X_{i, t}$ and $Y_{t}$ are firm-specific and macro-economic control vectors respectively ${ }^{33}$ By $C R_{i, t} \in\left\{\operatorname{CookESG} G_{i, t}\right.$, ClimateRisk $\left._{i, t}\right\}$, we denote our proxies for climate risk exposure discussed in Section 2. Hence, a positive and significant coefficient $\beta$ would indicate that regulatory climate risk disclosure carries relevant information for the determination of CDS spreads and slopes.

The regression equations (1) and (2) both represent a panel first-difference (FD) model, following Collin-Dufresne et al. (2001); Ericsson et al. (2009) by focusing on the effect of changes in the

\footnotetext{
${ }^{32}$ See, e.g., Lando and Mortensen (2005).

${ }^{33}$ We remark that we performed several robustness checks for our analysis. In particular, we also performed the same regressions based on yearly data. Initially, we opted for monthly regressions to find a balance between the different frequencies of the different data sources. We do not find a substantial difference from the regressions based on monthly data. These results can be obtained from the authors.
} 
exogenous variables on changes in the endogenous variable. However, we obtain estimates for our regression coefficients by performing simple (pooled) OLS on the differences series and exploiting our data's panel structure. By taking the first difference in each firm's time series, we effectively control for any time-invariant, unobserved heterogeneous effect. Indeed, an FD model is similar in spirit to a panel model for the levels, including (firm) fixed effects (FE), where the firm fixed effects are differenced away ${ }^{34}$ Both the forecasting element and the focus on changes in our panel setting, allow us to put more emphasis on the causal inference 35

In what follows, we mainly focus on the most liquid CDS contracts. Therefore, we discuss the results for the five-year CDS spreads and the term structure slopes using maturities of one and five years 36

\subsection{Base results}

In Table 4, we report the results for our baseline regression in Equation 1, where we use the CDS spread as the dependent variable $\left(S^{5 Y}\right)$. In all reported results, we allow for arbitrary correlations in the standard errors by clustering on SASB industries. By clustering on industry instead of an entity, we take a conservative stance. With 67 different industries in our sample, according to Petersen (2009), we should have a sufficiently high number of clusters to render unbiased standard errors.

[Table 4 about here.]

It was our expectation that climate risks, as disclosed in regulatory filings, drive up CDS spreads, given that greater exposure to risk should increase the risk premia required by investors. However, as we see from Table 4 , both climate risk measures, ClimateRisk and CookESG, are not significantly affecting CDS spreads. The coefficient for CookESG is even negative. The directional estimates

\footnotetext{
${ }^{34}$ For a model with only two time periods, the FD estimate and the fixed effects regression are even identical. For $\mathrm{T}>2$, the FD and FE estimators are very much related. The choice between an FE or FD model depends mostly on notions of relative efficiency, which depends on the assumption one is willing to make on the error term in the FE regression (Wooldridge, 2010). As a robustness check, we also perform FE regressions on the levels, which gives us estimates that are qualitatively similar to those reported for the FD regressions. These results are available on request.

${ }^{35}$ These estimates are unbiased, given the classical linear model assumptions, and consistent for large $N$ and small $T$, see Wooldridge (2012).

${ }^{36}$ We also repeated the same analysis for spreads of higher maturity contracts such as the ten and thirty-year contracts. However, we do not find significant effects of climate-risk disclosures at these longer horizons.
} 
for our control variables are consistent with expectations from previous literature throughout all the specifications and are often strongly significant ${ }^{37}$ Changes in business conditions, leverage, and interest rates turn out to be the main drivers of CDS spreads.

In an alternative setup, we split the sample into firms where climate risks are deemed material, and firms where climate risks are deemed not material. To perform this split, we rely on the SASB's materiality map and its Sustainable Industry Classification System ${ }^{38}$ SASB's materiality map creates a unique materiality profile for each industry. Based on the U.S. Supreme Court definition of materiality, it groups companies according to their similarities in their resource intensity and sustainability risks and opportunities. The materiality map identifies 26 sustainability-related business issues that are likely to affect the financial conditions or operating performance of companies within an industry. From those 26 issues, seven are climate risk-related. Following Matsumura et al. (2018), climate risk is considered to be material for an industry if three out of seven issues apply to that industry 39

[Table 5 about here.]

Results for this alternative setup are reported in Table 5. For CookESG, the $\beta$-parameter remains insignificant for both the material and the non-material industries. However, for ClimateRisk, we find a highly significant and positive $\beta$-parameter for the material industries, and an insignificant parameter for the non-material industries. Hence, while ClimateRisk suggests that regulatory climate risk disclosure affects CDS spreads, this is not the case for the CookESG measure. This observation is an indication that $10-\mathrm{K}$ filings contain at least some price relevant information, at least for firms in industries where climate risks are generally viewed as material. Furthermore, it suggests that the improved precision of the BERT algorithm is necessary to establish such a link.

\footnotetext{
${ }^{37}$ See, e.g., Han and Zhou $(2015)$. We remark that the sample contains a larger number of firms and covers a different period than that of Ericsson et al. (2009) and (Han and Zhou, 2015), which includes the recent financial crisis. Hence, our results may differ quantitatively in terms of the control variates.

$\sqrt[38]{\text { SASB Materiality map and the Sustainable Industry Classification System }}$

${ }^{39}$ Based on this rule, we identify the following industries for whom climate risk is considered to be a material issue: 'Coal operations', 'Construction Materials', 'Iron \& Steel Producers', 'Metals \& Mining', 'Oil \& Gas - Exploration \& Production', 'Oil \& Gas - Midstream', 'Oil \& Gas - Refining \& Marketing', 'Oil \& Gas - Services', 'Agricultural Products', 'Food Retailers \& Distributors', 'Meat, Poultry \& Dairy', 'Non-Alcoholic Beverages', 'Restaurants', 'Health Care Delivery', 'Electric Utilities \& Power Generators', 'Real Estate', 'Waste Management', 'Water Utilities \& Services', 'Forestry Management', 'Pulp \& Paper Products', 'Solar Technology \& Project developers', 'Chemicals', 'Containers \& Packaging', 'Hotels \& Lodging', 'Semiconductors', 'Cruise Lines' and 'Marine Transportation'
} 


\subsection{The Impact of the Paris Agreement}

Both Ilhan et al. (2019b) and Delis et al. (2019) find that the 2015 Paris Agreement was a pivotal point and that only afterwards climate change became price and risk relevant. To corroborate our finding, we test whether this is the case as well in our setting. Specifically, we ask whether the Paris Agreement had a significant impact on how and whether investors incorporate climate-relevant information from 10-K filings into CDS prices of different companies. To this end, we introduce a dummy variable into our baseline regression that marks the Paris Agreement in 2015. In particular, we estimate regression equations of the form

$$
\Delta S_{i, t+1}^{m}=\beta \Delta C R_{i, t}+\gamma\left(\Delta C R \times \text { Post }_{i, t}+\eta \Delta \text { Post }_{i, t}+\Phi \Delta X_{i, t}+\Theta \Delta Y_{t}+\epsilon_{i, t+1},\right.
$$

where Post is a dummy for the period after the Paris agreement.

[Table 6 about here.]

As the results in Table 6 indicate, the CookESG measure does not give any significant or intuitively appealing findings. The only significant effect, although just at a $10 \%$ significance, is for the period after the Paris agreement. Here, CookESG suggests that climate-risk disclosure after the Paris Agreement had a negative impact on CDS spreads for non-material industries. However, taking ClimateRisk as the relevant measure, we find that before the Paris Agreement, climate-risk disclosure in the 10-K filings did not influence CDS prices. However, after the Paris Agreement, climate-risk disclosure became a significant driver for the material industry in that it had, in line with our intuition, a positive effect on the level of CDS spreads.

\subsection{Differentiating transition and physical climate risks}

The interplay between transition risks and physical risks is critical in understanding the impact of climate change on companies' performance across sectors and geographies. Strong regulatory actions may avoid the worst physical impacts of climate change in the longer term, but also endanger firms that are affected by the regulation in the short term. Therefore, we ask whether we find some 
evidence if these two components of climate risk, transition and physical, are perceived differently by investors in the CDS market. Hence, we estimate the regression equation

$$
\Delta S_{i, t+1}^{m}=\beta_{T} \Delta \text { ClimateRisk-Trans }_{i, t}+\beta_{P} \Delta \text { ClimateRisk-Phys }_{i, t}++\Phi \Delta X_{i, t}+\Theta \Delta Y_{t}+\epsilon_{i, t+1},
$$

where, for the climate-disclosure measure $C R_{i, t}$, we use the physical and transition risk components of ClimateRisk.

[Table 7 about here.]

We report the results in Table 7. When we do not differentiate between material and non-material industries, we find only a weak impact of transition risk after the Paris Agreement in 2015. Physical risk disclosure in the 10-K filings does not seem to impact CDS spreads at all. However, if we focus on the material industries, we obtain a highly significant impact with a $p$-value below 0.01 . In line with our intuition, the impact is positive, i.e., transition climate-risk disclosure leads to higher credit spreads in material industries. Again, for physical risks, we do not find a statistically significant impact. We conjecture that the potential damage due to physical climate risks is highly uncertain, or investors believe that they will materialize in the far distant future (or both). Therefore, we also investigate whether physical risks will become significant for CDS with maturities beyond five years.

[Table 8 about here.]

In Table 8, we perform the regression on the CDS spreads for maturities of 10 and 30 years. As the results indicate, physical risks remain an insignificant driver of CDS spreads at these longer maturities in both the material and non-material industries, and in the period after the Paris Agreement. In contrast, during this period, the impact of transition risk remains significant at all horizons and, in particular, highly significant for the material industries.

\subsection{Regressing the slope of the CDS term structure}

As the previous findings suggest, climate risks and, in particular, transition risks have a significant effect on the levels of CDS spreads. We can now go one step further and investigate when, i.e., at 
what time horizon, investors expect the most severe impacts of climate risks. For that purpose, we analyze the impact of regulatory disclosures on the slope of the CDS term structure. If climate risk impacts all CDS maturities equally, the slope will not change. If investors believe that climate risks will have more severe impacts on certain time horizons, we expect to observe a significant change in the slope of the CDS term structure. Hence, we repeat the above regression exercises, but we replace the spread $S_{i, t+1}^{m}$ by the slope $Y_{i, t+1}^{m, n}$ between maturities $m$ and $n$. Furthermore, given the disappointing results using CookESG so far, we only focus on ClimateRisk.

[Table 9 about here.]

In Table 9, we summarize the results for the term structure regressions when we use ClimateRisk as the relevant measure. Due to liquidity concerns, we only focus on CDS contracts with up to 10year maturity. When we consider the whole period, we do not get any significant impact of climate disclosure on the slopes - even if we differentiate between material and non-material industries. However, when we take the Paris Agreement into account, the slope between the one-year and fiveyear maturity reacts significantly to regulatory climate-risk disclosure in the post-Paris Agreement period and for the material industries. For those industries, the slope becomes steeper. At the same time, the slope for longer maturities remains unaffected by climate disclosures.

[Table 10 about here.]

Repeating the same analysis for the slope of the CDS term structure, but this time splitting up the climate-risk disclosure into a transition and physical component, we find similar results. As Table 10 suggests that physical risks do not impact the CDS slopes. However, transition risks do play a role. Their strongest impact is on the slope between the one-year and five-year maturity and for the material industries. For higher maturities, also transition risks have no significant effect. In sum, the term structure results suggest that investors take note of transition risk over a time horizon of up to 5 years. At least as disclosed in regulatory findings, physical risks do not seem to affect risk expectations in the CDS market. 


\section{Conclusion}

Climate change is continuing to dominate headlines, and the impact of climate change-related risks on financial and capital markets is a growing concern for companies, investors, and regulators worldwide. Climate change is a topic that is increasingly affecting financial markets. Two key questions are whether financial markets reflect climate risks in prices, and how companies should report such climate risks to investors. A string of recent papers explores the potential pricing of climate change risk, using different climate risk measures and asset classes. Most use carbon emissions, which do not cover the entire spectrum of climate risks and are currently reported on a voluntary basis. Also, many results are based on equity prices, where there are potentially confounding effects of investor tastes in addition to risk pricing.

This paper contributes a novel metric of climate risk based on mandatory disclosure and state-ofthe-art natural language processing methods. Specifically, we use BERT to analyze 10-K reports that firms are required to file with the SEC. The key advantages of this measure are that it is mandatory and that it allows differentiating between transition and physical risks. This novel climate risk measure performs substantially better than older algorithms in extracting climate risk information from text data.

Using this novel measure, we demonstrate that CDS spreads are responsive to regulatory climaterisk disclosures, at least in industries where climate risks are expected to be material. To the best of our knowledge, our paper is the first study to demonstrate such an effect on CDS spreads. While some previous studies observe a premium on stock returns for firms exposed to climate risk, we find that climate risk affects CDS spreads and that the perceived risk is so substantial that it affects creditors. What is more, while equity prices could in parallel be driven by investors' taste, due to divestments (see, e.g., Hong and Kacperczyk (2009) and Pastor et al. (2020)), this alternative hypothesis is highly unlikely in the CDS market. Hence, our results highlight that climate risk is indeed interpreted as a financial risk.

Importantly, we show that only transition risks are being priced, not the physical risks of climate change. This finding suggests that the market responds distinctively to transition and physical risks. Transition risk is more sensitive to political developments. In line with that, we find that the price 
effect of transition risk increased with the Paris Climate Accord of 2015. Physical risks, on the other hand, are more complex and longer-term. However, even when analyzing CDS contracts extending to up to 30 years and analyzing the term structure of CDS spreads, we do not find a significant effect of physical risk. We cannot determine whether the reason is that investors believe physical risks are negligible, or whether 10-K filings fail to provide the information necessary to evaluate such risks. We leave this question for future research.

Overall, our results imply that climate risk disclosure as mandated by the SEC fulfills - at least to some extent - its purpose of informing investors about material risks and thereby limiting the risk of sudden adjustments in the future. While it certainly could be improved, we present evidence that the disclosed information affects the perceived riskiness of corporate debt, which implies that investors make use of the disclosed information. At the same time, our results leave open whether the current approach to disclosure works for physical risks. 


\section{References}

Andersson, M., Bolton, P., and Samama, F. (2016). Hedging climate risk. Financial Analysts Journal, $72(3): 13-32$.

Baldauf, M., Garlappi, L., and Yannelis, C. (2020). Does climate change affect real estate prices? Only if you believe in it. The Review of Financial Studies, 33(3):1256-1295.

Barth, F., Hübel, B., and Scholz, H. (2019). ESG and corporate credit spreads: Evidence from Europe. Working paper.

Berkman, H., Jona, J., and Soderstrom, N. S. (2019). Firm-specific climate risk and market valuation.

Blanco, R., Brennan, S., and Marsh, I. W. (2005). An empirical analysis of the dynamic relation between investment-grade bonds and credit default swaps. The Journal of Finance, 60(5):22552281.

Bolton, P. and Kacperczyk, M. T. (2020). Carbon premium around the world. Working paper.

Campbell, J. Y. and Taksler, G. B. (2003). Equity volatility and corporate bond yields. The Journal of Finance, 58(6):2321-2350.

Chen, L. H. and Gao, L. S. (2012). The pricing of climate risk. Journal of Financial and Economic Practice, 12(2):115-131.

Collin-Dufresne, P., Goldstein, R. S., and Spencer, M. J. (2001). The determinants of credit spread changes. The Journal of Finance, 56(6):2177-2207.

Delis, M. D., de Greiff, K., and Ongena, S. (2019). Being stranded with fossil fuel reserves? Climate policy risk and the pricing of bank loans. Working paper.

Devlin, J., Chang, M.-W., Lee, K., and Toutanova, K. (2019). BERT: Pre-training of deep bidirectional transformers for language understanding. In Proceedings of the 2019 Conference of the North American Chapter of the Association for Computational Linguistics: Human Language Technologies, volume 1, pages 4171-4186. 
Ericsson, J., Jacobs, K., and Oviedo, R. (2009). The determinants of credit default swap premia. Journal of Financial and Quantitative Analysis, 44(1):109-132.

Financial Stability Board (2017). Recommendations of the task force on climate-related financial disclosures.

Friberg, R. and Seiler, T. (2017). Risk and ambiguity in 10-ks: An examination of cash holding and derivatives use. Journal of Corporate Finance, 100(45):608-631.

Ginglinger, E. and Moreau, Q. (2019). Climate risk and capital structure. Working paper.

Görgen, M., Jacob, A., Nerlinger, M., Riordan, R., R. M., and Wilkens, M. (2019). Carbon risk. Working paper.

Grüning, M. (2011). Artificial intelligence measurement of disclosure (AIMD). European Accounting Review, 20(3):485-519.

Han, B. and Zhou, Y. (2015). Understanding the term structure of credit default swap spreads. Journal of Empirical Finance, 31:18-35.

Hong, H. and Kacperczyk, M. (2009). The price of sin: The effects of social norms on markets. Journal of Financial Economics, 93(1):15-36.

Hong, H., Li, and Xu (2017). Climate risks and market efficiency. Journal of Econometrics, 208(1):265-281.

Hope, O.-K., Hu, D., and Lu, H. (2016). The benefits of specific risk-factor disclosures. Review of Accounting Studies, 21(4):1005-1045.

Hsu, Li, and Tsou (2018). The pollution premium. Working paper.

Ilhan, E., Krueger, P., Sautner, Z., and Starks, L. T. (2019a). Institutional investors' views and preferences on climate risk disclosure. Working paper.

Ilhan, E., Sautner, Z., and Vilkov, G. (2019b). Carbon tail risk. The Review of Financial Studies (forthcoming). 
In, S. Y., Park, K. Y., and Monk, A. H. B. (2019). Is 'being green' rewarded in the market? An empirical investigation of decarbonization and stock returns. Working paper.

Jung, J., Herbohn, K., and Clarkson, P. (2018). Carbon risk, carbon risk awareness and the cost of debt financing. Journal of Business Ethics, 150(4):1151-1171.

Kim, D.-Y. and Kang, S.-W. (2018). Analysis of recognition of climate changes using word2vec. International Journal of Pure and Applied Mathematics, 120(6):5793-5807.

Kim, Y.-B., An, H. T., and Kim, J. D. (2015). The effect of carbon risk on the cost of equity capital. Journal of Cleaner Production, 93:279-287.

Krueger, P., Sautner, Z., and Starks, L. T. (2019). The importance of climate risks for institutional investors. Working paper.

Lando, D. and Mortensen, A. (2005). Revisiting the slope of the credit spread curve. Journal of Investment Management, 3(4).

Liesen, A., Figge, F., Hoepner, A., and Patten, D. M. (2017). Climate change and asset prices: Are corporate carbon disclosure and performance priced appropriately? Journal of Business Finance \& Accounting, 44(1-2):35-62.

Longstaff, F. A., Mithal, S., and Neis, E. (2005). Corporate yield spreads: Default risk or liquidity? new evidence from the credit default swap market. The Journal of Finance, 60(5):2213-2253.

Lopez-Lira, A. (2019). Risk factors that matter: Textual analysis of risk disclosures for the crosssection of returns. Working paper.

Luccioni, A. and Palacios, H. (2019). Using natural language processing to analyze financial climate disclosures. In Proceedings of the 36th International Conference on Machine Learning, Long Beach, California.

Lyon, T. P. and Maxwell, J. W. (2011). Greenwash: Corporate environmental disclosure under threat of audit. Journal of Economics \& Management Strategy, 20(1):3-41.

Mathiesen, K. (2018). Rating climate risks to credit worthiness. Nature Climate Change, 8:454-456. 
Matsumura, E. M., Prakash, R., and Vera-Muñoz, S. C. (2018). Capital market expectations of risk materiality and the credibility of managers' risk disclosure decisions. Working paper.

Palmiter, A. R. (2015). Climate change disclosure: A failed SEC mandate. Working paper.

Pastor, L., Stambaugh, R. F., and Taylor, L. A. (2020). Sustainable investing in equilibrium. Working paper ID 3559432, Social Science Research Network, Rochester, NY.

Pástor, L. and Veronesi, P. (2012). Uncertainty about government policy and stock prices. The Journal of Finance, 67(4):1219-1264.

Pástor, L. and Veronesi, P. (2013). Political uncertainty and risk premia. Journal of Financial Economics, 110(3):520-545.

Peters, M. E., Neumann, M., Iyyer, M., Gardner, M., Clark, C., Lee, K., and Zettlemoyer, L. (2018). Deep contextualized word representations. Working paper.

Petersen, M. A. (2009). Estimating standard errors in finance panel data sets: Comparing approaches. The Review of Financial Studies, 22(1):435-480.

Ramelli, S., Wagner, A. F., Zeckhauser, R. J., and Ziegler, A. (2018). Stock price rewards to climate saints and sinners: Evidence from the Trump election. NBER Working paper 25310.

SEC (2010). Commission guidance regarding disclosure related to climate change.

TCFD (2019). Task force on climate-related financial disclosures: Implementation guide.

The Economist Business Intelligence Unit (2015). The cost of inaction: Recognizing the value at risk from climate change.

Vaswani, A., Shazeer, N., Parmar, N., Uszkoreit, J., Jones, L., Gomez, A. N., Kaiser, Ł., and Polosukhin, I. (2017). Attention is all you need. In Advances in neural information processing systems, pages 5998-6008.

Wasim, R. (2019). Corporate (non) disclosure of climate change information. Columbia Law Review, 119(5):1311-1354. 
WEF (2020). The global risks report 2020.

Wooldridge, J. M. (2010). Econometric analysis of cross section and panel data. MIT press.

Wooldridge, J. M. (2012). Introductory econometrics: A modern approach. Nelson Education.

Zhang, Z. and Sabuncu, M. (2018). Generalized cross entropy loss for training deep neural networks with noisy labels. In Advances in neural information processing systems, pages 8778-8788.

Zhu, H. (2006). An empirical comparison of credit spreads between the bond market and the credit default swap market. Journal of Financial Services Research, 29(3):211-235. 


\section{Appendix}

\section{A CDS data collection}

CDS spreads are retrieved from Thomson Reuters Datastream using the Datastream Excel addin. We have located all cds spreads through the "find series" option in excel and searched for CDS data through the Datastream Navigator tool. Once the navigator is opened, we click on "Explore" and go through the following steps in the explorer:

1. Select "Credit Default Swaps" (twice)

2. Select "Thomson Reuters CDS by Tenor"

3. Select "No Restructure" (CDS clause - instrument-codes ending on "AX", this clause is chosen simply because it contains the most instruments)

4. Select wanted "Tenor" (All different maturities are done separately)

Once this selection is made, all the different available CDS contracts appear. Before downloading this bunch, we apply the following filters:

- Currency: United States Dollar denoted contracts only

- Market: United States only

Once the above steps and filters have been applied all remaining instruments are selected and downloaded. We repeat the above steps for all available maturities. Daily time series have been downloaded from 2009 till 2019.

Next, we filter out instruments that do not have data available for all the different maturities. Note that not all instruments have data for the entire period, this is not a problem. For the period for which that instrument has full data, the instrument is kept.

Finally, before ending up with our final CDS data set, instruments not complying with the standard Datastream mnemonic codes are excluded as well, e.g. those not ending on "AX" or having the wrong order. Also, negative spreads are excluded. 
We now observe daily CDS spreads for 767 instruments for maturities of ranging from six months to 30 years. 


\section{Tables}

Table 1. Model Performance

\begin{tabular}{lcccc}
\hline & \multicolumn{2}{c}{ CN Task } & \multicolumn{2}{c}{ TP Task } \\
\hline \multicolumn{1}{c}{ Model } & Acc & F1 & Acc & F1 \\
\hline Baseline & 81.07 & 82.03 & 58.60 & 48.60 \\
BERT-Single & 94.17 & 94.07 & $\mathbf{9 0 . 7 8}$ & $\mathbf{9 0 . 2 7}$ \\
BERT-Multitask & 98.06 & 98.02 & 85.44 & 82.36 \\
BERT-GCE & 94.17 & 94.07 & 90.29 & 89.68 \\
BERT-Multi-GCE & $\mathbf{9 9 . 5 1}$ & $\mathbf{9 9 . 5 0}$ & 89.81 & 88.45 \\
\hline
\end{tabular}


Table 2. Descriptive statistics

Descriptive statistics of all independent variables, five-year CDS spreads and the five-year minus one-year CDS term structure slope. ClimateRisk, Transition and Physical are climate risk scores based on our BERT algorithm, while CookESG is the one used in Berkman et al. (2019). $S^{5 Y}$ (in basis points) is the five-year CDS spread. $Y^{5 Y, 1 Y}$ (in basis points) is the five-year minus one-year CDS term structure slope. Lev (in percentage points) is the leverage ratio, defined as ratio between the book value of total liabilities and the sum of the book value of total liabilities and the market value of equity. ROA (in percentage points) is the return-over-assets, defined as the ratio of net income to total assets. $\mathrm{Vol}$ (in percentage points) is the daily return volatility over the last 180 trading days. $I R$ (in percentage points) is the interest rate. $B C$ (in percentage points) is the return on the S\&P500 index. The table presents the average value (Mean), standard deviation (Stdv), skewness (Skew) and excess kurtosis (Ex. kurt), as well as the minimum (Min), maximum (Max) and median (Median) values for each variable. The sample period ranges from February 2010 to December 2018.

\begin{tabular}{lrrrrrrr}
\hline & Mean & Stdv & Skew & Ex. Kurt & Min & Median & Max \\
\hline ClimateRisk & 0.11 & 0.13 & 1.79 & 3.27 & 0.00 & 0.06 & 0.84 \\
CookESG & 34.89 & 77.92 & 5.33 & 41.99 & 0.00 & 8.00 & 1036.00 \\
Physical & 0.03 & 0.04 & 3.18 & 24.66 & 0.00 & 0.02 & 0.58 \\
Transition & 0.07 & 0.11 & 2.00 & 3.78 & 0.00 & 0.02 & 0.67 \\
$S^{5 Y}(\mathrm{bp})$ & 169.95 & 189.59 & 3.08 & 12.92 & 11.10 & 103.74 & 1863.28 \\
$Y^{5 Y, 1 Y}(\mathrm{bp})$ & 98.22 & 105.81 & 2.45 & 9.40 & -1058.26 & 63.12 & 1046.76 \\
Lev (\%) & 47.54 & 21.07 & 0.52 & -0.55 & 4.58 & 44.32 & 99.66 \\
ROA (\%) & 1.16 & 2.52 & -6.12 & 255.87 & -96.08 & 1.07 & 39.39 \\
Vol (\%) & 1.79 & 0.91 & 3.18 & 22.36 & 0.41 & 1.55 & 14.67 \\
IR (\%) & 2.41 & 0.54 & 0.52 & -0.34 & 1.50 & 2.32 & 3.85 \\
BC (\%) & 0.90 & 3.41 & -0.34 & 0.53 & -8.55 & 1.15 & 10.23 \\
\hline
\end{tabular}


Table 3. Industry constituents

Industry constituents based on the SASB's Sustainable Industry Classification System. The table shows per industry the number of companies in our sample (\# F) and the number of firm-month observations (\# F-m). The sample period ranges from February 2010 to December 2018.

\begin{tabular}{|c|c|c|c|c|c|}
\hline Industry & $\# \mathbf{F}$ & \# F-m & Industry & $\# \mathbf{F}$ & \# F-m \\
\hline Real Estate & 32 & 3118 & Electric Utilities \& Power Generators & 27 & 2509 \\
\hline Insurance & 23 & 2364 & Multiline and Specialty Retailers \& Distributors & 20 & 1939 \\
\hline Industrial Machinery \& Goods & 19 & 1944 & Chemicals & 18 & 1662 \\
\hline Oil \& Gas - Exploration \& Production & 18 & 1716 & Telecommunication Services & 13 & 1043 \\
\hline Software \& IT Services & 12 & 1176 & Containers \& Packaging & 11 & 969 \\
\hline Electrical \& Electronic Equipment & 11 & 960 & Medical Equipment \& Supplies & 11 & 1035 \\
\hline Home Builders & 10 & 1010 & Hardware & 10 & 954 \\
\hline Health Care Delivery & 9 & 762 & Apparel, Accessories \& Footwear & 9 & 913 \\
\hline Aerospace \& Defense & 9 & 860 & Professional \& Commercial Services & 9 & 954 \\
\hline Iron \& Steel Producers & 9 & 937 & Media \& Entertainment & 9 & 848 \\
\hline Semiconductors & 8 & 752 & Biotechnology \& Pharmaceuticals & 8 & 512 \\
\hline Processed Foods & 7 & 684 & Oil \& Gas - Midstream & 7 & 496 \\
\hline Commercial Banks & 7 & 683 & Household \& Personal Products & 7 & 717 \\
\hline Oil \& Gas - Services & 6 & 411 & Managed Care & 6 & 532 \\
\hline Metals \& Mining & 6 & 485 & Casinos \& Gaming & 5 & 432 \\
\hline Airlines & 5 & 491 & Auto Parts & 5 & 486 \\
\hline Food Retailers \& Distributors & 4 & 371 & Building Products \& Furnishings & 4 & 424 \\
\hline Tobacco & 4 & 347 & Hotels \& Lodging & 4 & 289 \\
\hline Restaurants & 3 & 314 & Waste Management & 3 & 318 \\
\hline Mortgage Finance & 3 & 221 & Consumer Finance & 3 & 258 \\
\hline Investment Banking \& Brokerage & 3 & 318 & Air Freight \& Logistics & 3 & 314 \\
\hline Advertising \& Marketing & 3 & 243 & Health Care Distributors & 3 & 315 \\
\hline Construction Materials & 3 & 318 & Agricultural Products & 3 & 187 \\
\hline Alcoholic Beverages & 3 & 262 & Rail Transportation & 3 & 318 \\
\hline Appliance Manufacturing & 2 & 212 & Oil \& Gas - Refining \& Marketing & 2 & 137 \\
\hline EMS \& ODM & 2 & 134 & Non-Alcoholic Beverages & 2 & 212 \\
\hline E-commerce & 2 & 212 & Forestry Management & 2 & 212 \\
\hline Drug Retailers & 2 & 131 & Pulp \& Paper Products & 2 & 143 \\
\hline Asset Management \& Custody Activities & 2 & 162 & Toys \& Sporting Goods & 2 & 212 \\
\hline Automobiles & 1 & 106 & Engineering \& Construction Services & 1 & 102 \\
\hline Internet Media \& Services & 1 & 106 & Road Transportation & 1 & 77 \\
\hline Gas Utilities \& Distributors & 1 & 106 & Coal Operations & 1 & 15 \\
\hline Leisure Facilities & 1 & 106 & Car Rental \& Leasing & 1 & 90 \\
\hline Meat, Poultry \& Dairy & 1 & 106 & & & \\
\hline
\end{tabular}


Table 4. Monthly FD regression results for base setup

This table shows the regression results for a panel first difference regression of the form: $\Delta S_{i, t+1}^{m}=\beta \Delta C R_{i, t}+$ $\Phi \Delta X_{i, t}+\Theta \Delta Y_{t}$, where $C R_{i, t}$ is either one of our two measures (CookESG or ClimateRisk), $X$ is a vector of firm-specific controls, and $Y$ a vector of macro-economic controls. Coefficients are estimated by OLS on the pooled differences. Standard errors (in brackets) are clustered on the SASB industry level. The sample period ranges from February 2010 to December 2018. By *,**, and ${ }^{* * *}$ we denote $p$-levels below $10 \%, 5 \%$, and 1\%, respectively.

\begin{tabular}{lcc}
\hline & $(\mathrm{I})$ & $(\mathrm{II})$ \\
& $\Delta S^{5 Y}$ & $\Delta S^{5 Y}$ \\
\hline$\Delta$ CookESG & -0.002 & \\
& $(0.015)$ & \\
$\Delta$ ClimateRisk & & 11.232 \\
& & $(7.930)$ \\
$\Delta B C$ & $-0.281^{* * *}$ & $-0.266^{* * *}$ \\
& $(0.060)$ & $(0.059)$ \\
$\Delta I R$ & $25.451^{* * *}$ & $25.312^{* * *}$ \\
& $(5.697)$ & $(5.415)$ \\
$\Delta I R 2$ & $-5.086^{* * *}$ & $-5.080^{* * *}$ \\
& $(1.152)$ & $(1.086)$ \\
$\Delta$ Lev & $2.466^{* * *}$ & $2.427^{* * *}$ \\
& $(0.299)$ & $(0.302)$ \\
$\Delta R O A$ & 0.121 & 0.139 \\
$\Delta V$ ol & $(0.108)$ & $(0.113)$ \\
& $2.983^{*}$ & 2.440 \\
No. Observations & $(1.716)$ & $(1.569)$ \\
R-squared & 41288 & 39224 \\
\hline
\end{tabular}


Table 5. Monthly FD regression results, controlling for expected climate change materiality

This table shows the regression results for a panel first difference regression of the form: $\Delta S_{i, t+1}^{m}=\beta \Delta C R_{i, t}+$ $\Phi \Delta X_{i, t}+\Theta \Delta Y_{t}$, where $C R_{i, t}$ is either one of our two measures (CookESG or ClimateRisk), $X$ and $Y$ are vectors of firm-specific and macro-economic controls respectively. Coefficients are estimated by performing pooled OLS using the difference and this for different subsamples. Materiality subsamples are determined on expected climate change materiality on an industry level based on Matsumura et al. (2018) and the SASB's materiality map. Standard errors are clustered on an industry level. The sample period ranges from February 2010 to December 2018. By *,**, and ${ }^{* * *}$ we denote $p$-levels below $10 \%, 5 \%$, and $1 \%$, respectively.

\begin{tabular}{lcccc}
\hline & $(\mathrm{I})$ & $(\mathrm{II})$ & $(\mathrm{III})$ & $(\mathrm{IV})$ \\
& Non-Mat & Mat & Non-Mat & Mat \\
& $\Delta S^{5 Y}$ & $\Delta S^{5 Y}$ & $\Delta S^{5 Y}$ & $\Delta S^{5 Y}$ \\
\hline$\Delta$ CookESG & -0.007 & 0.018 & & \\
& $(0.013)$ & $(0.037)$ & & \\
$\Delta$ ClimateRisk & & & -5.976 & $29.091^{* * *}$ \\
& & & $(12.117)$ & $(11.242)$ \\
$\Delta B C$ & $-0.276^{* * *}$ & $-0.293^{* * *}$ & $-0.254^{* * *}$ & $-0.293^{* * *}$ \\
& $(0.076)$ & $(0.090)$ & $(0.072)$ & $(0.095)$ \\
$\Delta I R$ & $29.061^{* * *}$ & $17.912^{* *}$ & $29.005^{* * *}$ & $17.769^{* *}$ \\
& $(7.285)$ & $(7.769)$ & $(6.839)$ & $(7.840)$ \\
$\Delta I R 2$ & $-5.773^{* * *}$ & $-3.648^{* *}$ & $-5.769^{* * *}$ & $-3.666^{* *}$ \\
& $(1.493)$ & $(1.570)$ & $(1.374)$ & $(1.648)$ \\
$\Delta$ Lev & $2.302^{* * *}$ & $2.753^{* * *}$ & $2.235^{* * *}$ & $2.764^{* * *}$ \\
& $(0.362)$ & $(0.520)$ & $(0.365)$ & $(0.521)$ \\
$\Delta R O A$ & 0.009 & $0.413^{*}$ & 0.032 & $0.406^{*}$ \\
$\Delta$ Vol & $(0.116)$ & $(0.230)$ & $(0.125)$ & $(0.231)$ \\
& 2.227 & 3.975 & 1.285 & 3.945 \\
& $(2.381)$ & $(2.418)$ & $(2.037)$ & $(2.411)$ \\
\hline No. Observations & 28284 & 13004 & 26802 & 12422 \\
R-squared & 0.033 & 0.063 & 0.032 & 0.062 \\
\hline
\end{tabular}


Table 6. Monthly FD regression results, controlling for both materiality and the Paris agreement

This table shows the regression results for a panel first difference regression of the form: $\Delta S_{i, t+1}^{m}=\beta \Delta C R_{i, t}+$ $\eta \Delta$ Post $_{i, t}+\gamma \Delta(\text { Post } \times C R)_{i, t}+\Phi \Delta X_{i, t}+\Theta \Delta Y_{t}$, where $C R_{i, t}$ is either one of our two measures (CookESG or ClimateRisk), $X$ and $Y$ are vectors of firm-specific and macro-economic controls respectively. Coefficients are estimated by performing pooled OLS using the difference and this for different subsamples. Materiality subsamples are determined on expected climate change materiality on an industry level based on Matsumura et al. (2018) and the SASB's materiality map. To measure the impact of the Paris agreement, we include 'Post' as a dummy for the subsequent period and interact this dummy with our climate risk exposure variable. Standard errors are clustered on an industry level. The sample period ranges from February 2010 to December 2018. By $* * *$, and $* * *$ we denote $p$-levels below $10 \%, 5 \%$, and $1 \%$, respectively.

\begin{tabular}{|c|c|c|c|c|c|c|}
\hline & (I) & (II) & (III) & $(\mathrm{IV})$ & $(\mathrm{V})$ & $(\mathrm{VI})$ \\
\hline & All & Non-Mat & Mat & All & Non-Mat & Mat \\
\hline & $\Delta S^{5 Y}$ & $\Delta S^{5 Y}$ & $\Delta S^{5 Y}$ & $\Delta S^{5 Y}$ & $\Delta S^{5 Y}$ & $\Delta S^{5 Y}$ \\
\hline$\triangle$ CookESG & $\begin{array}{r}-0.003 \\
(0.010)\end{array}$ & $\begin{array}{c}-0.004 \\
(0.012)\end{array}$ & $\begin{array}{c}-0.018 \\
(0.044)\end{array}$ & & & \\
\hline$\Delta$ CookESG $\times$ Post & $\begin{array}{c}0.006 \\
(0.026)\end{array}$ & $\begin{array}{r}-0.011^{*} \\
(0.007)\end{array}$ & $\begin{array}{c}0.097 \\
(0.063)\end{array}$ & & & \\
\hline$\Delta$ ClimateRisk & & & & $\begin{array}{l}-6.596 \\
(13.130)\end{array}$ & $\begin{array}{l}-1.808 \\
(12.789)\end{array}$ & $\begin{array}{c}2.120 \\
(14.426)\end{array}$ \\
\hline$\Delta$ ClimateRisk $\times$ Post & & & & $\begin{array}{c}56.530 \\
(39.822)\end{array}$ & $\begin{array}{c}-11.510 \\
(12.569)\end{array}$ & $\begin{array}{l}106.203^{* *} \\
(45.286)\end{array}$ \\
\hline$\Delta$ Post & $\begin{array}{l}8.532^{* * *} \\
(2.603)\end{array}$ & $\begin{array}{l}5.814^{* * *} \\
(1.778)\end{array}$ & $\begin{array}{l}12.755^{*} \\
(7.514)\end{array}$ & $\begin{array}{c}2.965 \\
(2.733)\end{array}$ & $\begin{array}{l}6.603^{* * *} \\
(2.346)\end{array}$ & $\begin{array}{c}-2.388 \\
(4.106)\end{array}$ \\
\hline$\triangle B C$ & $\begin{array}{c}-0.272^{* * *} \\
(0.059)\end{array}$ & $\begin{array}{c}-0.270^{* * *} \\
(0.075)\end{array}$ & $\begin{array}{c}-0.277^{* * *} \\
(0.089)\end{array}$ & $\begin{array}{c}-0.256^{* * *} \\
(0.058)\end{array}$ & $\begin{array}{c}-0.248^{* * *} \\
(0.072)\end{array}$ & $\begin{array}{c}-0.276^{* * *} \\
(0.094)\end{array}$ \\
\hline$\Delta I R$ & $\begin{array}{l}27.119^{* * *} \\
(5.893)\end{array}$ & $\begin{array}{l}30.126^{* * *} \\
(7.459)\end{array}$ & $\begin{array}{c}20.856^{* *} \\
(8.651)\end{array}$ & $\begin{array}{l}26.953^{* * *} \\
(5.611)\end{array}$ & $\begin{array}{l}30.137^{* * *} \\
(7.000)\end{array}$ & $\begin{array}{l}20.530^{* *} \\
(8.627)\end{array}$ \\
\hline$\Delta I R 2$ & $\begin{array}{c}-5.356^{* * *} \\
(1.178)\end{array}$ & $\begin{array}{c}-5.946^{* * *} \\
(1.522)\end{array}$ & $\begin{array}{c}-4.127^{* *} \\
(1.658)\end{array}$ & $\begin{array}{c}-5.342^{* * *} \\
(1.113)\end{array}$ & $\begin{array}{c}-5.954^{* * *} \\
(1.401)\end{array}$ & $\begin{array}{c}-4.110^{* *} \\
(1.731)\end{array}$ \\
\hline$\Delta L e v$ & $\begin{array}{c}2.453^{* * *} \\
(0.298)\end{array}$ & $\begin{array}{l}2.294^{* * *} \\
(0.361)\end{array}$ & $\begin{array}{l}2.726^{\text {*** }} \\
(0.516)\end{array}$ & $\begin{array}{c}2.419^{* * *} \\
(0.301)\end{array}$ & $\begin{array}{l}2.226^{* * *} \\
(0.364)\end{array}$ & $\begin{array}{c}2.739^{* * *} \\
(0.519)\end{array}$ \\
\hline$\triangle R O A$ & $\begin{array}{c}0.120 \\
(0.108)\end{array}$ & $\begin{array}{c}0.008 \\
(0.115)\end{array}$ & $\begin{array}{c}0.417^{*} \\
(0.231)\end{array}$ & $\begin{array}{c}0.138 \\
(0.113)\end{array}$ & $\begin{array}{c}0.031 \\
(0.125)\end{array}$ & $\begin{array}{c}0.401^{*} \\
(0.233)\end{array}$ \\
\hline$\Delta V o l$ & $\begin{array}{c}2.706 \\
(1.679)\end{array}$ & $\begin{array}{c}2.042 \\
(2.356)\end{array}$ & $\begin{array}{c}3.431 \\
(2.263)\end{array}$ & $\begin{array}{c}2.112 \\
(1.511)\end{array}$ & $\begin{array}{l}1.083 \\
(2.010)\end{array}$ & $\begin{array}{c}3.317 \\
(2.195)\end{array}$ \\
\hline No. Observations & 41288 & 28284 & 13004 & 39224 & 26802 & 12422 \\
\hline R-squared & 0.041 & 0.033 & 0.066 & 0.042 & 0.032 & 0.068 \\
\hline
\end{tabular}


Table 7. Monthly FD regression results, when separating physical and transition climate risk

This table shows the regression results for a panel first difference regression of the form: $\Delta S_{i, t+1}^{m}=$ $\beta \Delta C R_{i, t}+\eta \Delta$ Post $_{i, t}+\gamma \Delta(\text { Post } \times C R)_{i, t}+\Phi \Delta X_{i, t}+\Theta \Delta Y_{t}$, where $C R_{i, t}$ is the vector containing both Physical and Transition. Both physical and transition climate risk are based on Item 1a in firms' 10-K's. Coefficients are estimated by performing pooled OLS using the difference and this for different subsamples. Materiality subsamples are determined on expected climate change materiality on an industry level based on citematsumura2018capital and the SASB's materiality map. To measure the impact of the Paris agreement, we include 'Post' as a dummy for the subsequent period and interact this dummy with our climate risk exposure variable. Standard errors are clustered on an industry level. The sample period ranges from February 2010 to December 2018. By *, ${ }^{* *}$, and ${ }^{* * *}$ we denote $p$-levels below $10 \%, 5 \%$, and $1 \%$, respectively.

\begin{tabular}{lccc}
\hline & $(\mathrm{I})$ & $(\mathrm{II})$ & $(\mathrm{III})$ \\
& All & Non-Mat & Mat \\
& $\Delta S^{5 Y}$ & $\Delta S^{5 Y}$ & $\Delta S^{5 Y}$ \\
\hline$\Delta$ Physical & 7.305 & -0.496 & 20.175 \\
& $(10.253)$ & $(10.347)$ & $(19.812)$ \\
$\Delta$ Transition & 1.645 & 15.450 & -1.944 \\
& $(17.075)$ & $(22.031)$ & $(16.798)$ \\
$\Delta$ Physical $\times$ Post & -25.009 & -26.677 & 39.777 \\
& $(31.509)$ & $(23.435)$ & $(101.669)$ \\
$\Delta$ Transition $\times$ Post & $87.157^{*}$ & -0.282 & $123.773^{* * *}$ \\
& $(44.752)$ & $(14.957)$ & $(43.537)$ \\
$\Delta$ Post & 3.935 & $6.563^{* * *}$ & -1.236 \\
& $(2.453)$ & $(2.292)$ & $(4.415)$ \\
$\Delta$ Lev & $2.417^{* * *}$ & $2.226^{* * *}$ & $2.738^{* * *}$ \\
$\Delta$ ROA & $(0.300)$ & $(0.364)$ & $(0.517)$ \\
& 0.138 & 0.030 & $0.404^{*}$ \\
$\Delta$ Vol & $(0.113)$ & $(0.125)$ & $(0.234)$ \\
& 2.087 & 1.070 & 3.321 \\
$\Delta$ IR & $(1.502)$ & $(2.010)$ & $(2.184)$ \\
$\Delta$ IR2 & $26.947^{* * *}$ & $30.129^{* * *}$ & $20.561^{* *}$ \\
$\Delta$ BC & $(5.611)$ & $(7.017)$ & $(8.593)$ \\
& $-5.341^{* * *}$ & $-5.954^{* * *}$ & $-4.111^{* *}$ \\
No. Observations & $(1.113)$ & $(1.404)$ & $(1.728)$ \\
R-squared & $-0.256^{* * *}$ & $-0.248^{* * *}$ & $-0.278^{* * *}$ \\
\hline & $(0.058)$ & $(0.072)$ & $(0.094)$ \\
\hline & 39224 & 26802 & 12422 \\
& 0.042 & 0.032 & 0.069 \\
\hline
\end{tabular}


Table 8. Monthly FD regression results for $10 \mathrm{Y}$ and $30 \mathrm{Y}$ spreads

This table shows the regression results for a panel first difference regression of the form: $\Delta S_{i, t+1}^{m}=\beta \Delta C R_{i, t}+$ $\eta \Delta$ Post $_{i, t}+\gamma \Delta(\text { Post } \times C R)_{i, t}+\Phi \Delta X_{i, t}+\Theta \Delta Y_{t}$, where $C R_{i, t}$ is either ClimateRisk or the vector containing both Physical and Transition. Coefficients are estimated by performing pooled OLS using the difference and this for different subsamples. Materiality subsamples are determined on expected climate change materiality on an industry level based on Matsumura et al. (2018) and the SASB's materiality map. To measure the impact of the Paris agreement, we include 'Post' as a dummy for the subsequent period and interact this dummy with our climate risk exposure variable. Standard errors are clustered on an industry level. The sample period ranges from February 2010 to December 2018. By *, **, and *** we denote $p$-levels below 10\%, $5 \%$, and $1 \%$, respectively.

\begin{tabular}{|c|c|c|c|c|c|c|c|c|}
\hline & $\begin{array}{c}(\mathrm{I}) \\
\text { All } \\
\Delta S^{10 Y}\end{array}$ & $\begin{array}{c}(\mathrm{II}) \\
\text { Mat } \\
\Delta S^{10 Y}\end{array}$ & $\begin{array}{c}(\mathrm{III}) \\
\text { All } \\
\Delta S^{10 Y}\end{array}$ & $\begin{array}{c}(\mathrm{IV}) \\
\text { Mat } \\
\Delta S^{10 Y}\end{array}$ & $\begin{array}{c}(\mathrm{V}) \\
\text { All } \\
\Delta S^{30 Y}\end{array}$ & $\begin{array}{c}(\mathrm{VI}) \\
\text { Mat } \\
\Delta S^{30 Y}\end{array}$ & $\begin{array}{c}(\mathrm{VII}) \\
\text { All } \\
\Delta S^{30 Y}\end{array}$ & $\begin{array}{c}\text { (VIII) } \\
\text { Mat } \\
\Delta S^{30 Y}\end{array}$ \\
\hline$\Delta$ ClimateRisk & $\begin{array}{l}-4.350 \\
(12.266)\end{array}$ & $\begin{array}{c}6.378 \\
(15.107)\end{array}$ & & & $\begin{array}{l}-2.942 \\
(11.794)\end{array}$ & $\begin{array}{c}4.908 \\
(14.900)\end{array}$ & & \\
\hline$\Delta$ ClimateRisk $\times$ Post & $\begin{array}{c}49.426 \\
(36.487)\end{array}$ & $\begin{array}{l}99.756^{* *} \\
(39.903)\end{array}$ & & & $\begin{array}{c}42.587 \\
(32.731)\end{array}$ & $\begin{array}{l}89.997^{* *} \\
(34.938)\end{array}$ & & \\
\hline$\Delta$ Physical & & & $\begin{array}{l}7.062 \\
(9.155)\end{array}$ & $\begin{array}{c}21.106 \\
(17.365)\end{array}$ & & & $\begin{array}{l}7.140 \\
(9.147)\end{array}$ & $\begin{array}{c}21.005 \\
(15.949)\end{array}$ \\
\hline$\Delta$ Transition & & & $\begin{array}{c}4.423 \\
(17.073)\end{array}$ & $\begin{array}{c}2.759 \\
(18.667)\end{array}$ & & & $\begin{array}{c}5.697 \\
(17.402)\end{array}$ & $\begin{array}{c}1.091 \\
(18.802)\end{array}$ \\
\hline$\Delta$ Physical $\times$ Post & & & $\begin{array}{c}-29.841 \\
(27.662)\end{array}$ & $\begin{array}{c}21.506 \\
(85.124)\end{array}$ & & & $\begin{array}{c}-32.245 \\
(26.849)\end{array}$ & $\begin{array}{c}11.376 \\
(80.722)\end{array}$ \\
\hline$\Delta$ Transition $\times$ Post & & & $\begin{array}{r}79.626^{*} \\
(41.886)\end{array}$ & $\begin{array}{l}119.011^{* * *} \\
(40.603)\end{array}$ & & & $\begin{array}{c}71.454^{*} \\
(37.627)\end{array}$ & $\begin{array}{l}109.452^{* * *} \\
(36.476)\end{array}$ \\
\hline$\Delta$ Post & $\begin{array}{c}4.613 \\
(2.809)\end{array}$ & $\begin{array}{c}-1.731 \\
(4.213)\end{array}$ & $\begin{array}{c}5.501^{* *} \\
(2.582)\end{array}$ & $\begin{array}{c}-0.353 \\
(4.404)\end{array}$ & $\begin{array}{c}5.149^{*} \\
(2.837)\end{array}$ & $\begin{array}{c}-1.199 \\
(4.421)\end{array}$ & $\begin{array}{c}5.944^{* *} \\
(2.677)\end{array}$ & $\begin{array}{c}0.109 \\
(4.658)\end{array}$ \\
\hline$\triangle B C$ & $\begin{array}{c}-0.260^{* * *} \\
(0.053)\end{array}$ & $\begin{array}{c}-0.297^{* * *} \\
(0.086)\end{array}$ & $\begin{array}{c}-0.260^{* * *} \\
(0.053)\end{array}$ & $\begin{array}{c}-0.298^{* * *} \\
(0.086)\end{array}$ & $\begin{array}{c}-0.261^{* * *} \\
(0.050)\end{array}$ & $\begin{array}{c}-0.311^{* * *} \\
(0.082)\end{array}$ & $\begin{array}{c}-0.261^{* * *} \\
(0.050)\end{array}$ & $\begin{array}{c}-0.313^{* * *} \\
(0.082)\end{array}$ \\
\hline$\Delta I R$ & $\begin{array}{l}28.064^{* * *} \\
(5.500)\end{array}$ & $\begin{array}{l}26.228^{* *} \\
(10.401)\end{array}$ & $\begin{array}{l}28.056^{* * *} \\
(5.501)\end{array}$ & $\begin{array}{c}26.279^{* *} \\
(10.354)\end{array}$ & $\begin{array}{l}30.483^{* * *} \\
(5.434)\end{array}$ & $\begin{array}{l}32.946^{* * *} \\
(10.811)\end{array}$ & $\begin{array}{l}30.474^{* * *} \\
(5.436)\end{array}$ & $\begin{array}{l}32.998^{* * *} \\
(10.763)\end{array}$ \\
\hline$\Delta I R 2$ & $\begin{array}{c}-5.441^{* * *} \\
(1.073)\end{array}$ & $\begin{array}{c}-5.283^{* *} \\
(2.053)\end{array}$ & $\begin{array}{c}-5.440^{* * *} \\
(1.074)\end{array}$ & $\begin{array}{c}-5.287^{* * *} \\
(2.048)\end{array}$ & $\begin{array}{c}-5.936^{* * *} \\
(1.103)\end{array}$ & $\begin{array}{c}-6.677^{* * *} \\
(2.315)\end{array}$ & $\begin{array}{c}-5.935^{* * *} \\
(1.104)\end{array}$ & $\begin{array}{c}-6.681^{* * *} \\
(2.309)\end{array}$ \\
\hline$\Delta L e v$ & $\begin{array}{l}2.275^{* * *} \\
(0.271)\end{array}$ & $\begin{array}{l}2.615^{* * *} \\
(0.471)\end{array}$ & $\begin{array}{l}2.274^{* * *} \\
(0.271)\end{array}$ & $\begin{array}{l}2.614^{* * *} \\
(0.469)\end{array}$ & $\begin{array}{l}2.201^{* * *} \\
(0.258)\end{array}$ & $\begin{array}{l}2.553^{* * *} \\
(0.448)\end{array}$ & $\begin{array}{l}2.200^{* * *} \\
(0.258)\end{array}$ & $\begin{array}{c}2.553^{* * *} \\
(0.446)\end{array}$ \\
\hline$\triangle R O A$ & $\begin{array}{c}0.074 \\
(0.096)\end{array}$ & $\begin{array}{c}0.408^{*} \\
(0.248)\end{array}$ & $\begin{array}{c}0.075 \\
(0.096)\end{array}$ & $\begin{array}{c}0.411^{*} \\
(0.249)\end{array}$ & $\begin{array}{c}0.061 \\
(0.096)\end{array}$ & $\begin{array}{c}0.435^{*} \\
(0.263)\end{array}$ & $\begin{array}{c}0.061 \\
(0.096)\end{array}$ & $\begin{array}{c}0.438^{*} \\
(0.264)\end{array}$ \\
\hline$\Delta V o l$ & $\begin{array}{c}1.345 \\
(1.368)\end{array}$ & $\begin{array}{c}1.604 \\
(1.779)\end{array}$ & $\begin{array}{c}1.319 \\
(1.361)\end{array}$ & $\begin{array}{c}1.601 \\
(1.772)\end{array}$ & $\begin{array}{c}1.414 \\
(1.339)\end{array}$ & $\begin{array}{c}1.001 \\
(1.713)\end{array}$ & $\begin{array}{c}1.389 \\
(1.333)\end{array}$ & $\begin{array}{c}0.995 \\
(1.708)\end{array}$ \\
\hline No. Observations & 39224 & 12422 & 39224 & 12422 & 39224 & 12422 & 39224 & 12422 \\
\hline R-squared & 0.043 & 0.067 & 0.044 & 0.067 & 0.042 & 0.062 & 0.042 & 0.062 \\
\hline
\end{tabular}




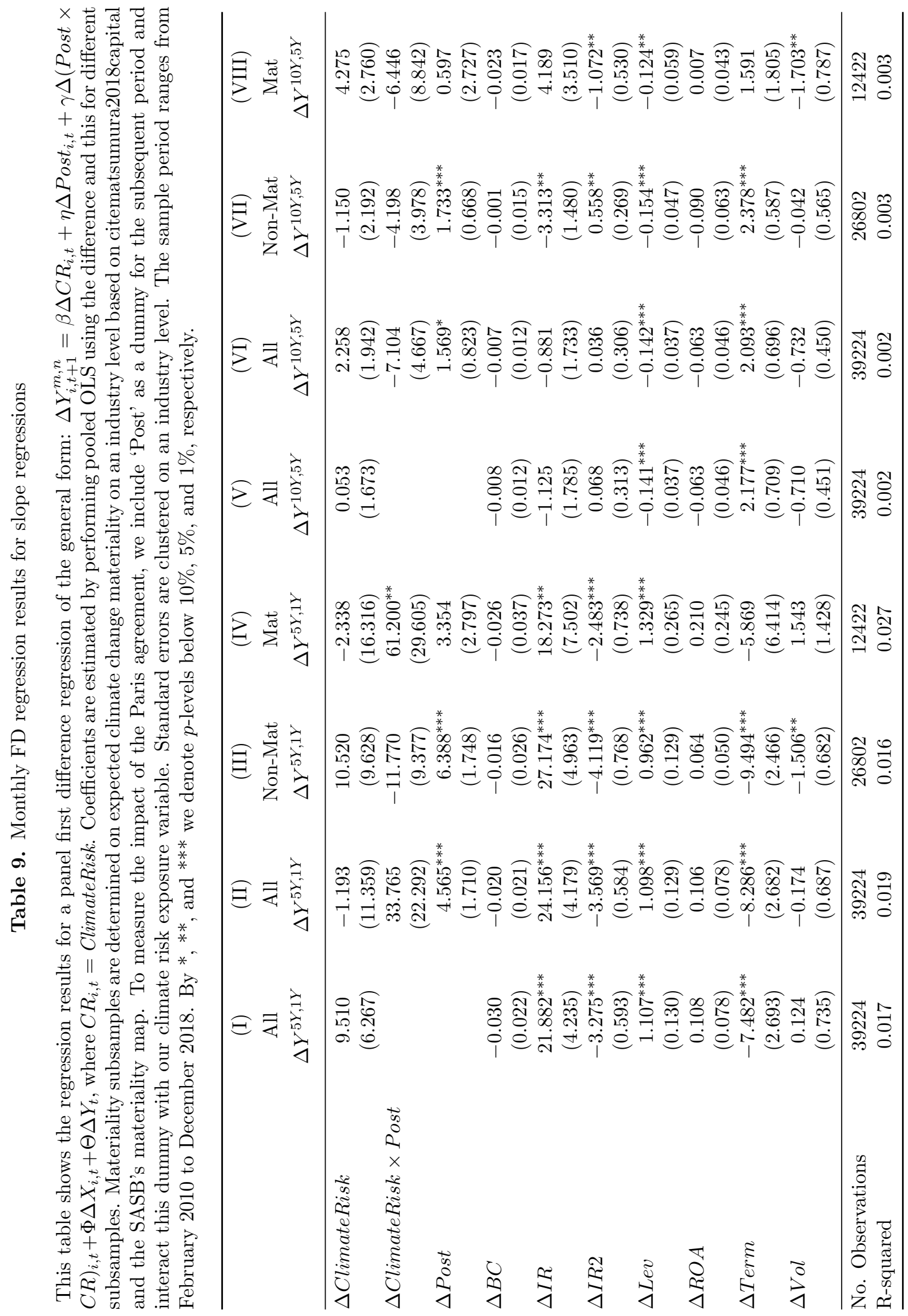

41 


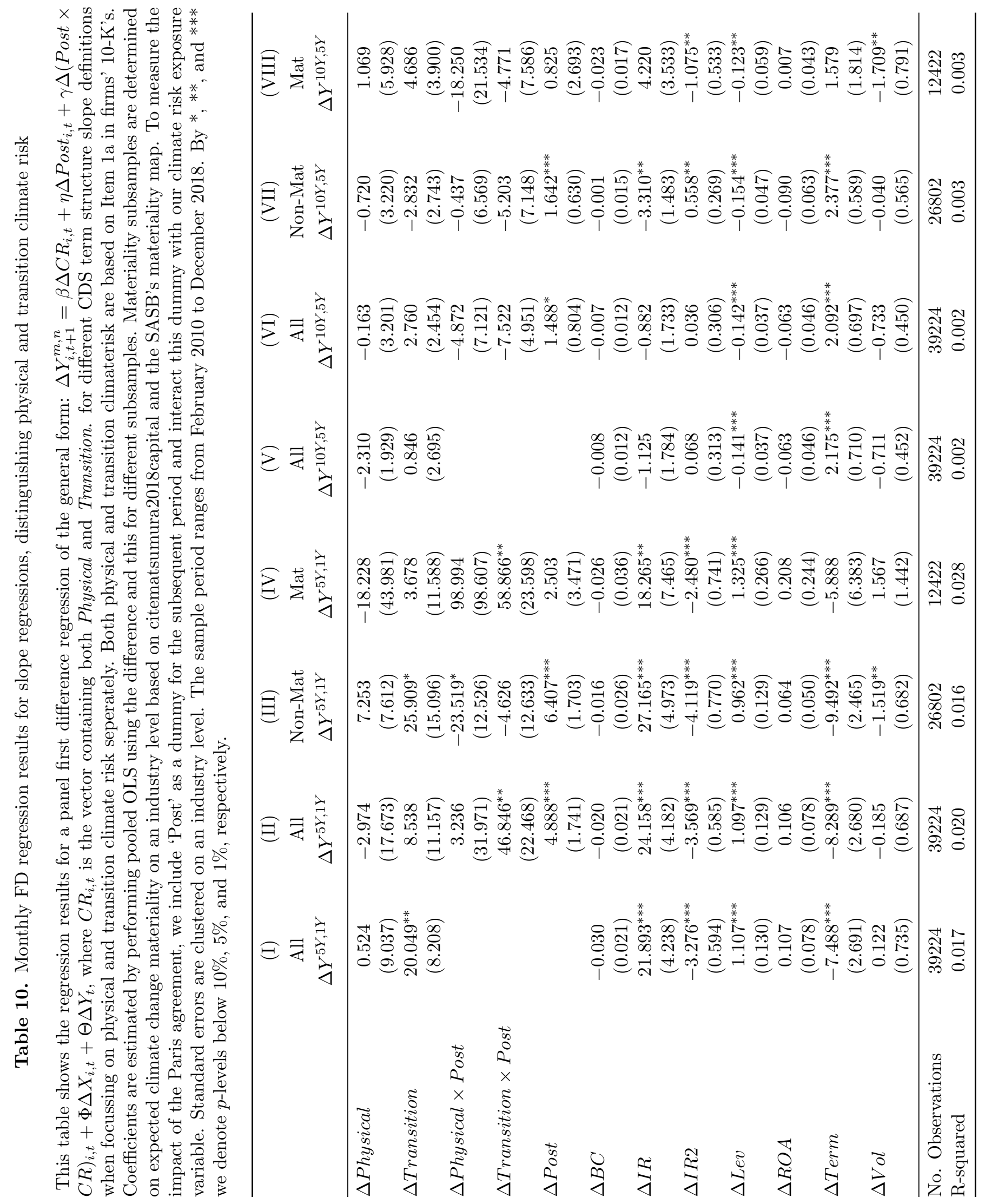




\section{Figures}

Figure 1. Climate risk score average and key percentiles over time, material vs. non-material industries

This figure presents the average value, as well as the 10th, 25th, 50th, 75th and 90th percentile of our climate risk score over time for material vs. non-material industries separately. Panel (a) presents these values for ClimateRisk while panel (b) presents results for CookESG. Materiality subsamples are determined on expected climate change materiality on an industry level, based on Matsumura et al. (2018) and the SASB's materiality map. The sample period ranges from February 2010 to December 2018.

(a) ClimateRisk

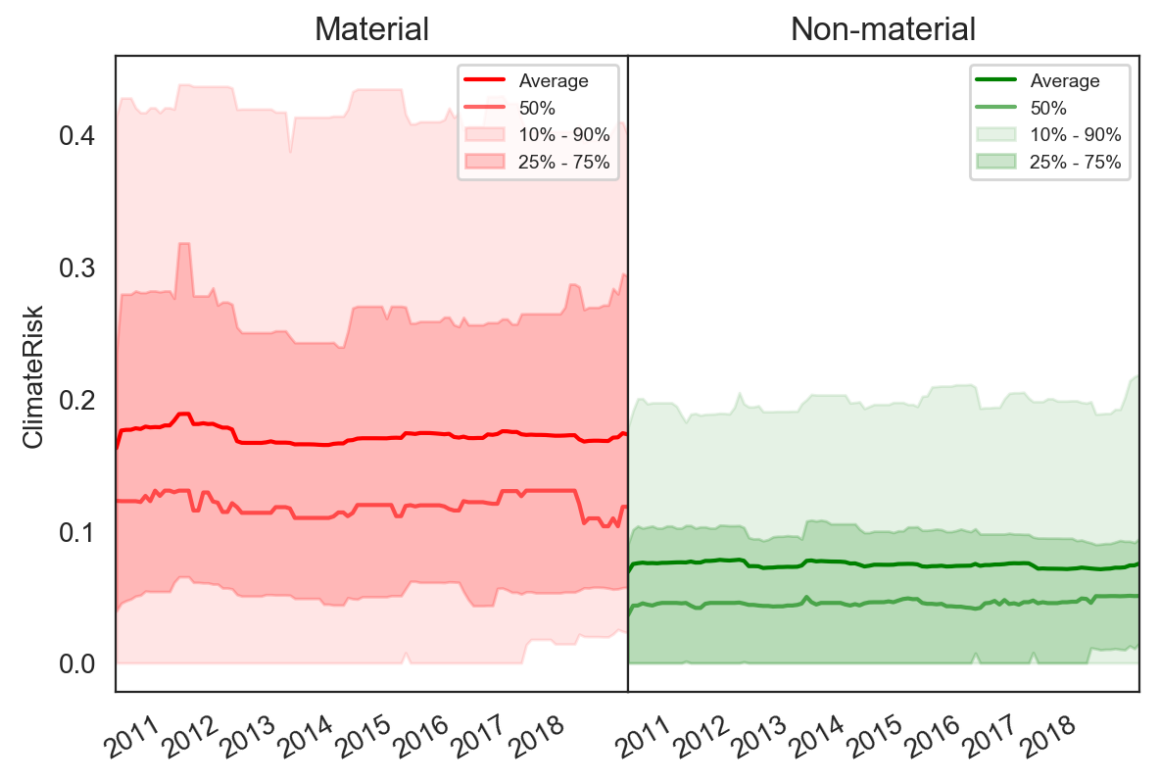

(b) CookESG

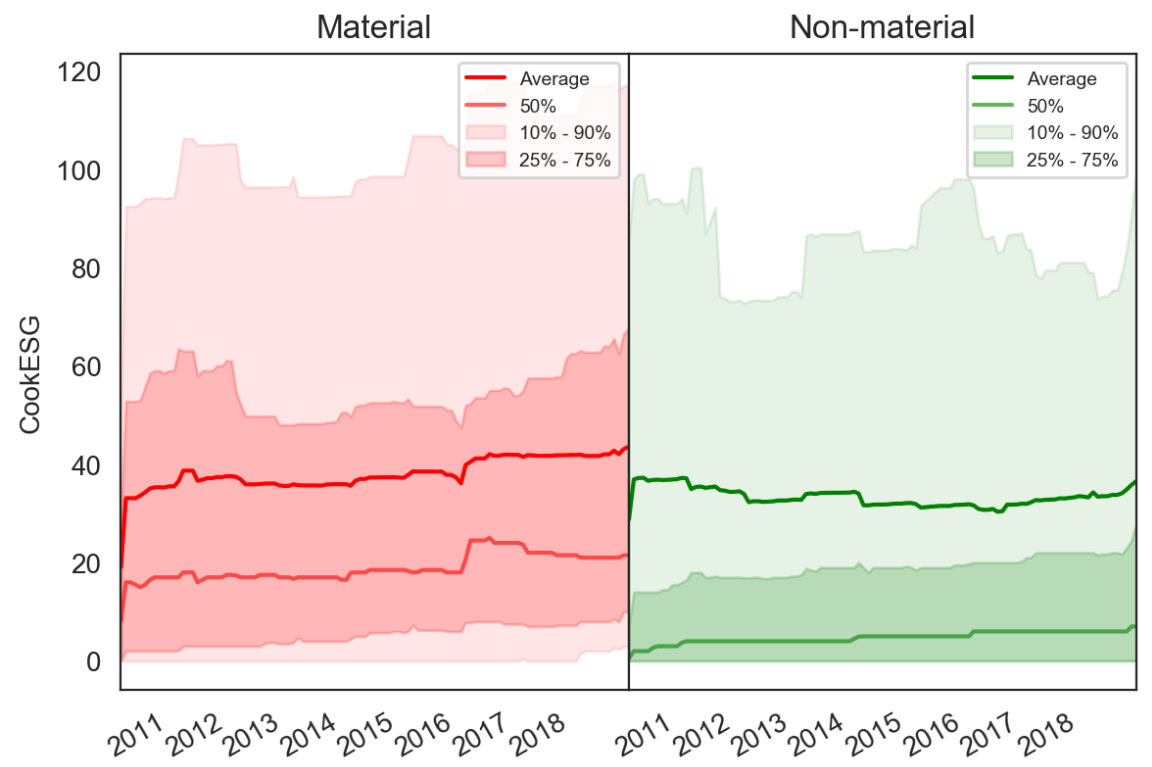


Figure 2. Industry averages

Figure shows the industry (equal-weighted) average and industry median values for for our two climate risk scores. Panel (a) presents results for CookESG, while panel (b) presents results for ClimateRisk. Industry classification is based on the SASB's Sustainable Industry Classification System (SICS). The sample period ranges from February 2010 to December 2018.

(a) CookESG

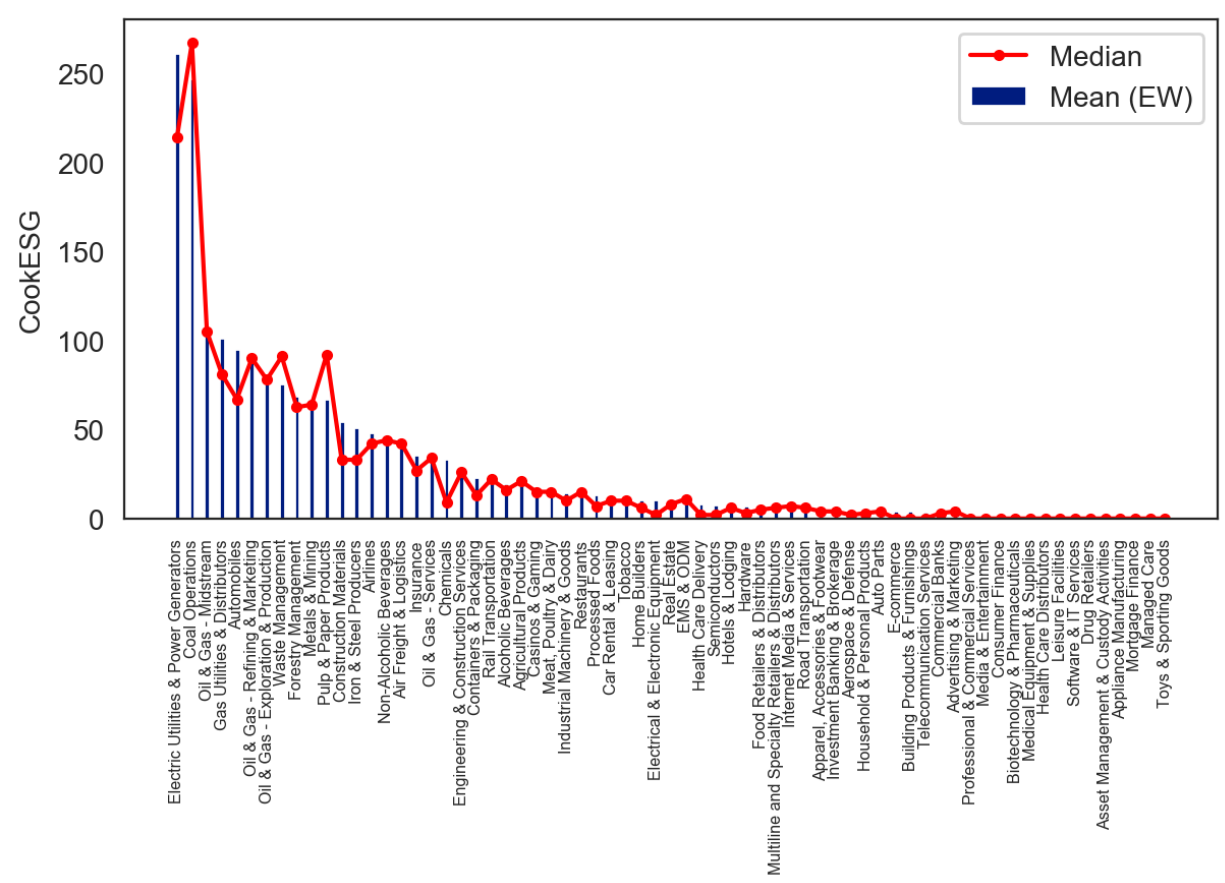

(b) ClimateRisk

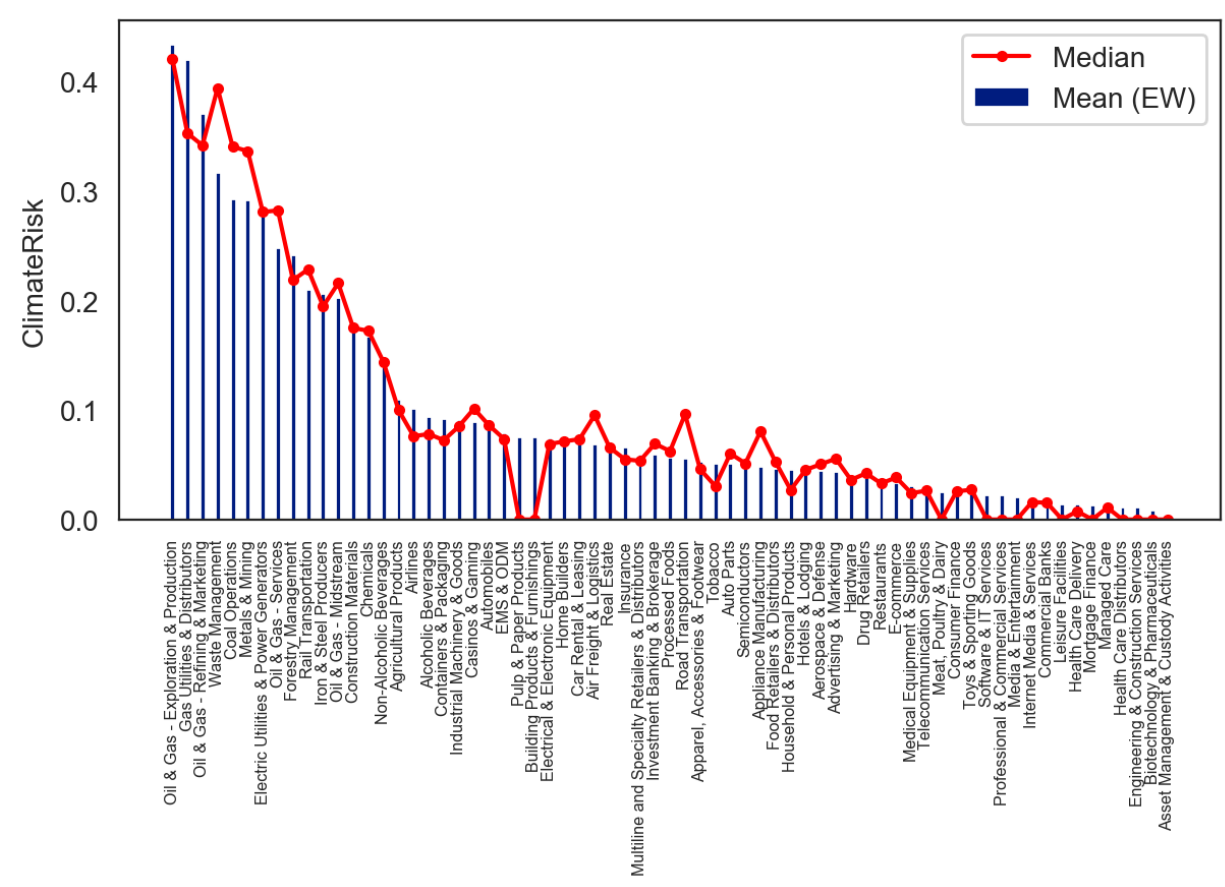


Figure 3. Fractions of firms disclosing climate change related risk

Panel (a) shows the fraction of firms that have a minimum level of climate risk disclosure in their annual 10-K filings, based on our two measures. Companies are categorized disclosing if their score surpasses a certain threshold value. For CookESG the minimum score is set at 2, while for ClimateRisk it is set at 0.05. Panel (b) shows the corresponding graph for the fraction of firms that have a minimum level of either physical or transition climate risk disclosure in their annual 10-K filings. The sample period ranges from February 2010 to December 2018.

(a) Disclosing climate risk

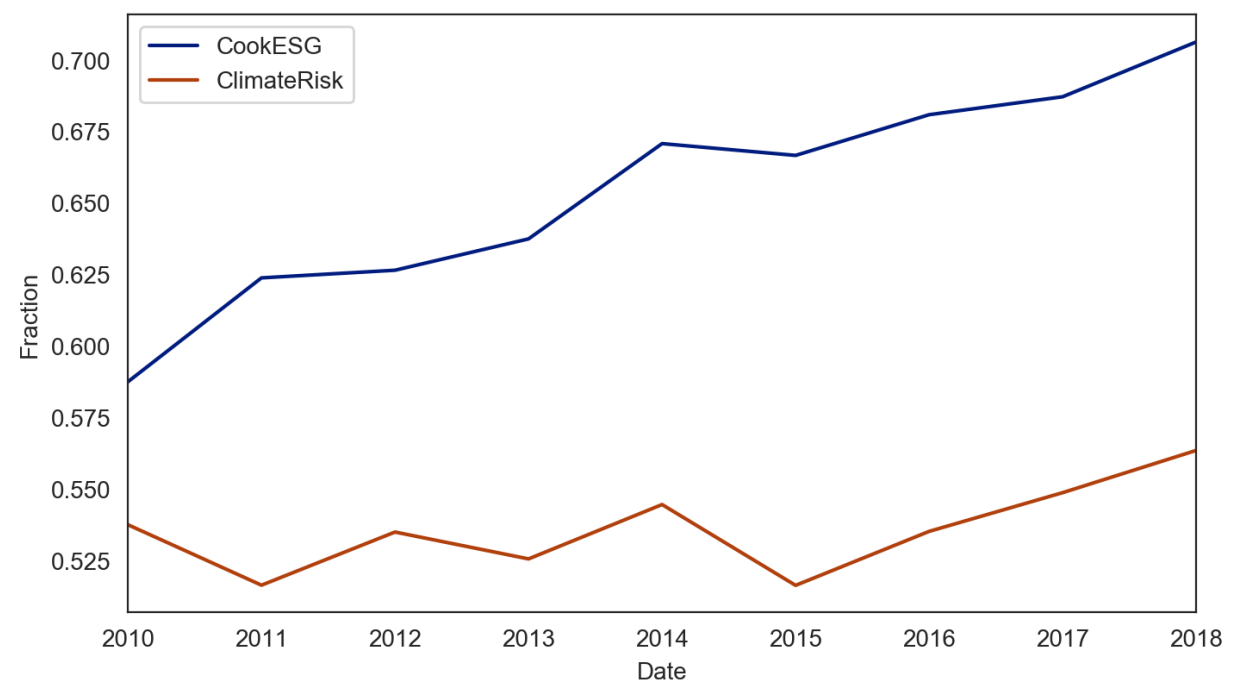

(b) Disclosing physical and transition risk

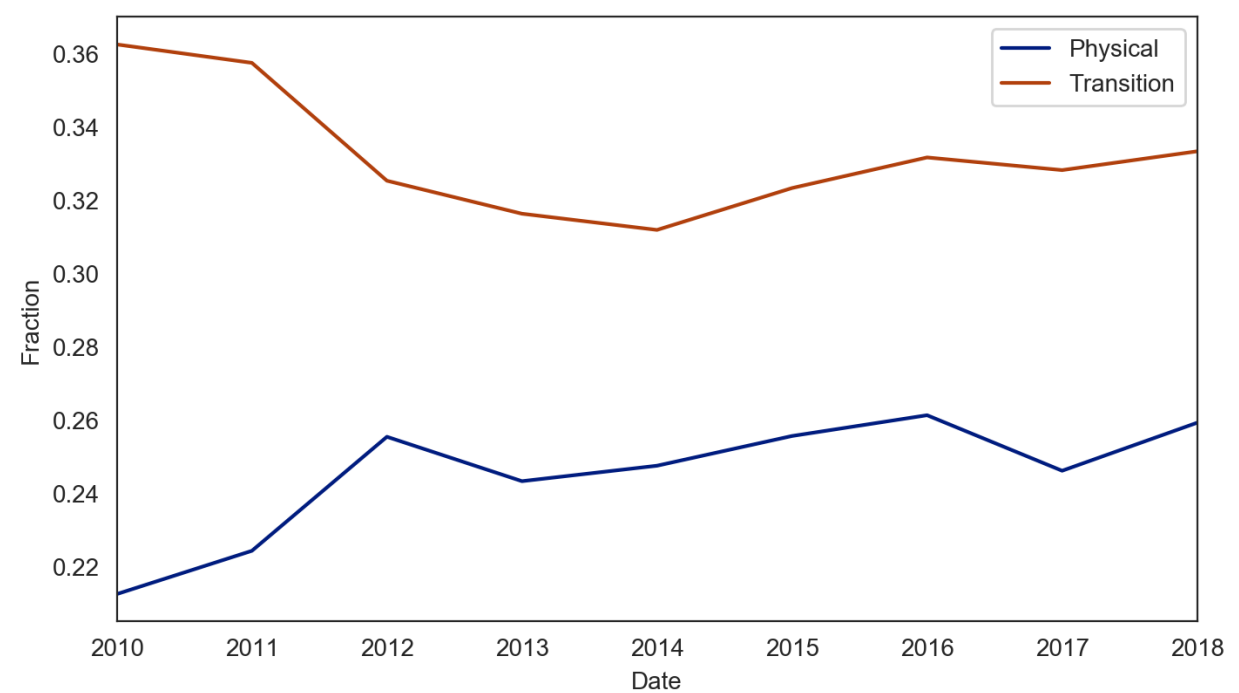


Figure 4. Average CDS spreads and term structure

For the different rating classes, panel (a) and (b) present average five-year CDS spreads, while panel (c) and (d) present average term structures. The sample period ranges from February 2010 to December 2018.

(a) Investment - 5Y spread

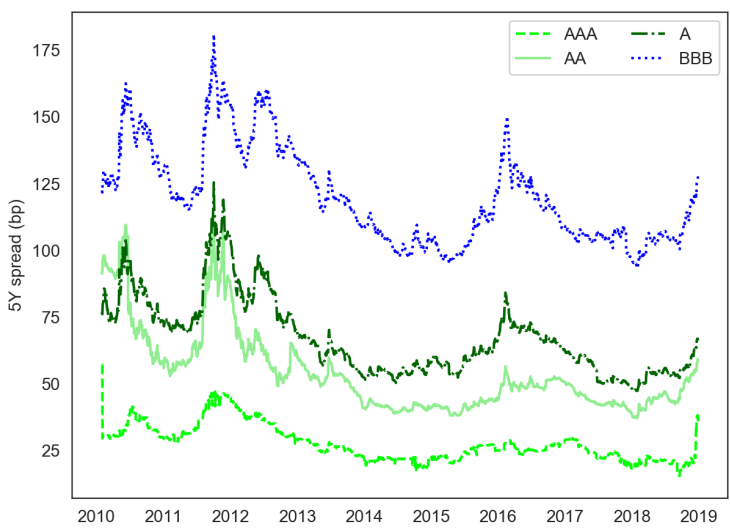

(c) Average tern structure Investment

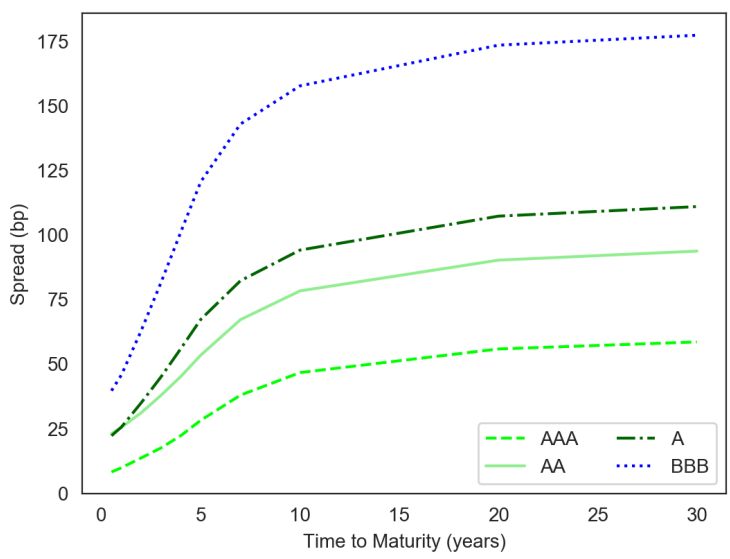

(b) Non-Investment - 5Y spread

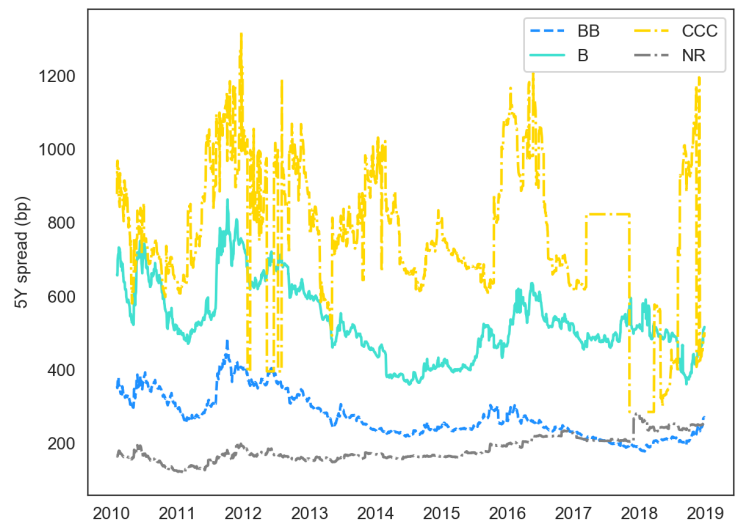

(d) Average tern structure Non-Investment

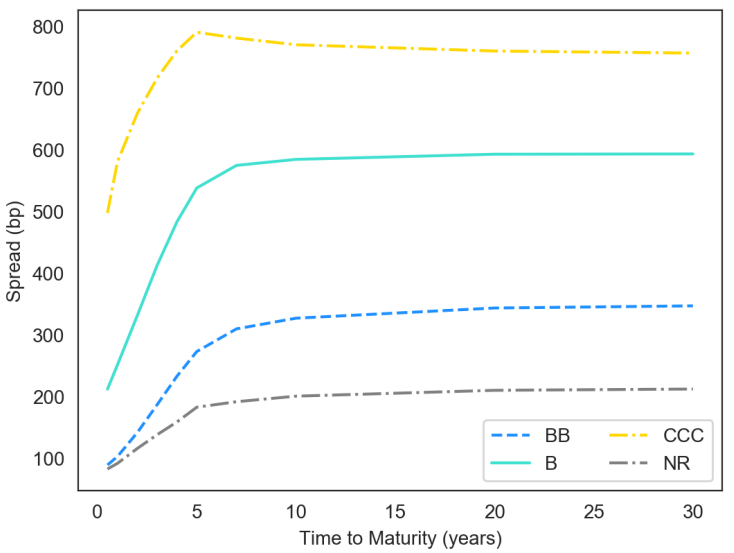

